\title{
Performance Research of Materials and Engineering Application of Overburden Strata Separation-Zone Grouting Technology
}

\author{
Wanpeng Huang $\mathbb{D}^{1,2}$ Huanyu Li $\mathbb{D}^{1},{ }^{1}$ Gang Sun, ${ }^{1,3}$ Donghai Jiang, ${ }^{1}$ and Yanfa Gao ${ }^{1}$ \\ ${ }^{1}$ College of Energy and Mining Engineering, Shandong University of Science and Technology, Qingdao 266590, China \\ ${ }^{2}$ State Key Laboratory of Coal Mining and Clean Utilization, Beijing 100013, China \\ ${ }^{3}$ Daizhuang Coal Mine, Shandong Energy Group Co. Ltd., Jining 272000, China
}

Correspondence should be addressed to Wanpeng Huang; hwp20033@sdust.edu.cn and Huanyu Li; 202083010029@sdust.edu.cn

Received 31 August 2021; Accepted 15 December 2021; Published 7 January 2022

Academic Editor: Robert Černý

Copyright (c) 2022 Wanpeng Huang et al. This is an open access article distributed under the Creative Commons Attribution License, which permits unrestricted use, distribution, and reproduction in any medium, provided the original work is properly cited.

\begin{abstract}
To solve the ground subsidence problem associated with thick coal seam mining under the railway in the Tangshan Mine, the technology of overburden strata separation-zone grouting (OSSG) was proposed. Based on the analysis of the full height overlying strata structure in the range of the six working face areas of the second mining district, the spatial distribution characteristics of the separation zone within the overlying strata are obtained after fully mining the six working faces. Then, emphasis was placed on the selection ratio of grouting materials and the hydrodynamic properties of different grout types, and grouting grout with a high concentration, slow precipitation rate, and good stability was obtained by taking fly ash and local clay as aggregates. The designed grout concentration was approximately $40 \%$; the bulk density was approximately 1.20 ; and the clay content in the aggregates was approximately $40-50 \%$. The separation-zone grouting plan was designed for the six working faces, and continuous grouting technology with the characteristics of multiple separation zones within the full-height section with a large flow and a high concentration was proposed to form a complete grouting system and reasonable grouting process. After engineering verification, the technology has an ash injection ratio of $24.2 \%$, a grouting ratio of $100.3 \%$, and a reduction in the ground subsidence ratio of $51.5 \%$, effectively reducing mining damage to the ground surface and ensuring the safe operation of ground surface railways. Simultaneously, this advancement improves the resource recovery rate of coal mines and provides greater benefits for mining enterprises.
\end{abstract}

\section{Introduction}

After implementing large scale, longwall face mining, due to the existence of free space, the overlying rock roof will produce movement damage, and the ground surface will sink, which will seriously affect the safety of ground surface buildings [1-4]. In the process of dynamic movement and destruction of the overburden roof from top to bottom, a large number of bed separation spaces will be formed within a specific area of the stratum. The technology of OSSG uses filling material to inject the separation zone to control the bending deformation of the overburden rock, which plays an important role in reducing the volume and velocity of the rock formation, thereby controlling ground subsidence [5-7].

The technology of OSSG has been successfully applied in the Soviet Union, Poland, the United States, and other countries. In China, grouting and subsidence reduction experiments have been successfully conducted in the Fushun Laohutai Mine, Xinwen Huafeng Mine, Yanzhou Dongtan Mine, Yanzhou Jining No. 2 Well, Zaozhuang Tianchen Mine, Datun Xuzhuang Mine, and Kailuan Tangshan Mine. Relevant experts at home and abroad have conducted indepth research on overburden movement and separation development laws, overburden separation grouting mechanisms, separation layer filling process system optimization 
strategies, separation layer filling and settlement reduction effect evaluation methods, and so on and have achieved a series of results [8-13]. In addition to the abovementioned influencing factors, in OSSG technology, another important factor that restricts the separation layer grouting settlement reduction effect is the selected filling material and its slurry properties. At present, attention to this factor is still relatively low at home and abroad, and relevant systematic and in-depth research results are still rare. The filling grout is injected into the surrounding rock space after the separation layer and fully adheres to the surrounding rock mass. On the one hand, it "supports" the rock formation above the separation layer, and on the other hand, it "compacts" the rock layer below the separation layer, thus effectively reducing the movement of strata. This requires that the filling slurry material has efficient bonding properties and self-solidification properties. At the same time, the overburden strata separation-zone grouting (OSSG) technology is generally constructed from the ground surface to the underground strata through a long-distance grouting borehole, which puts forward higher requirements on the fluidity, concentration, and precipitation speed of the slurry $[14,15]$.

In summary, it is a research topic with important practical value to find or configure a kind of grouting slurry with a high concentration, slow precipitation rate, and good stability. Based on the in-depth analysis of the mechanism of overburden separation grouting for subsidence reduction, this paper focuses on the composition characteristics of the two main proportioning materials of fly ash and clay and the sedimentation speed and hydromechanical properties of a fly ash slurry; a mixed slurry of clay and fly ash and a clay slurry is experimentally studied; and a reasonable grouting concentration is determined, which provides a basis for the preparation of the slurry in the grouting project. The research results have been successfully applied in the Kailuan Tangshan coal mine, and a good separation grouting effect has been achieved.

\section{Engineering Background}

2.1. Engineering Situations. The Tangshan coal mine of Kailuan Mining Group has an annual output of more than 3 million tons of raw coal. It is the company's main production mine. However, the large amount of ground surface pressure coal severely restricts the sustainable development of the Tangshan coal mine. Among them, the Jingshan Railway, which runs through the center of the Tangshan coal mine, is a national Class I railway. The geological reserves of compressed coal are more than 200 million tons, accounting for nearly half of the mine reserves. To increase the coal production capacity and extend the service life of the mine, it was decided to use overburden strata separation-zone grouting (OSSG) technology to reduce subsidence to mine coal pillars on both sides of the railway. The technology is preliminarily planned to be carried out in the second mining district, which is located below level 11 and above level 13 of the mine. The ground elevation is about $+14 \mathrm{~m}$. Nine coal seams are mainly mined. The mining elevation is $-550-740 \mathrm{~m}$, and the coal seam inclination is $5-17^{\circ}$, with an average of $10^{\circ}$. The coal seam is $9.5-12 \mathrm{~m}$ thick, with an average thickness of $10 \mathrm{~m}$. The Jingshan Railway is located above the center of the second railway zone, and the railway runs from southwest to northeast. The Tier 2 area is divided into 6 working mining faces along the inclined direction, from south to north (from shallow to deep), that is, T2191, T2192, T2193(1), T2193(2), T2194, and T2195, as shown in Figure 1 . The mining sequence is $\mathrm{T} 2191 \longrightarrow \mathrm{T} 2195 \longrightarrow$ $\mathrm{T} 2192 \longrightarrow \mathrm{T} 2194 \longrightarrow \mathrm{T} 2193(1) \longrightarrow \mathrm{T} 2193(2)$. The working face adopts comprehensive mechanized top-coal caving technology for mining, and all caving methods are implemented to manage the roof. The old roof of the 9 th coal seam working face is gray fine sandstone with a thickness of approximately $14.5 \mathrm{~m}$, and the main component is argillaceous cementation, horizontal bedding, thin-layered; the direct roof is a gray sandy mudstone with a thickness of approximately $4 \mathrm{~m}$; and the main component is argillaceous, sandy, silicon clay cementation.

2.2. Overlying Rock Structure Analysis. The strata in the Tangshan minefield from bottom to top consists of Ordovician limestone, the Middle Carboniferous Benxi Formation (also known as Tangshan Formation), the Upper Carboniferous Kaiping Formation, the Upper Carboniferous Zhaogezhuang Formation, the Lower Permian System Shanxi Formation (also known as the Damiaozhuang Formation), the Lower Permian Lower Shihezi Formation (also known as Tangjiazhuang Formation), the Upper Permian Upper Shihezi Formation (also known as Guye Formation), and a Quaternary loose water-bearing layer.

To study the physical and mechanical properties of the rock in the grouting section on the 9th coal seam, all the bedrock sections of the stratum with a depth of 240-430 $\mathrm{m}$ were cored to conduct physical and mechanical rock property tests. The test contents include compressive strength, tensile strength, deformation (elasticity modulus and Poisson's ratio), apparent density (bulk density) parameters, and so on. The results are shown in Table 1, and the statistics of the rock thickness and compressive strength of the bedrock section are shown in Figure 2.

The grouting lithology of the bedrock on the 9th coal seams mainly consists of various sandstone layers. In the 190 m-thick rock layer in the bedrock section with a hole depth of $240-430 \mathrm{~m}$, the thickness of various sandstones is $187.53 \mathrm{~m}$, accounting for $98.7 \%$ of all rock pillars. The compressive strength ranges of various rocks are as follows: coarse sandstone 54.6-123.2 MPa, with an average strength of $88.9 \mathrm{MPa}$; medium sandstone $71.3-143.1 \mathrm{MPa}$, with an average strength of $107.2 \mathrm{MPa}$; fine sandstone 54.1-164.4 MPa, with an average strength of 109.2 $\mathrm{MPa}$; siltstone $6.1-152.0 \mathrm{MPa}$, with an average strength of 82.1 $\mathrm{MPa}$; and mudstone 55.5-71.7 $\mathrm{MPa}$, with an average strength of $63.6 \mathrm{MPa}$. Weighted calculation of the compressive strength test results of various strata overlying the 9th coal seam was performed. The average compressive strength of the strata is $94.01 \mathrm{MPa}$ and is therefore considered hard overlying strata. 


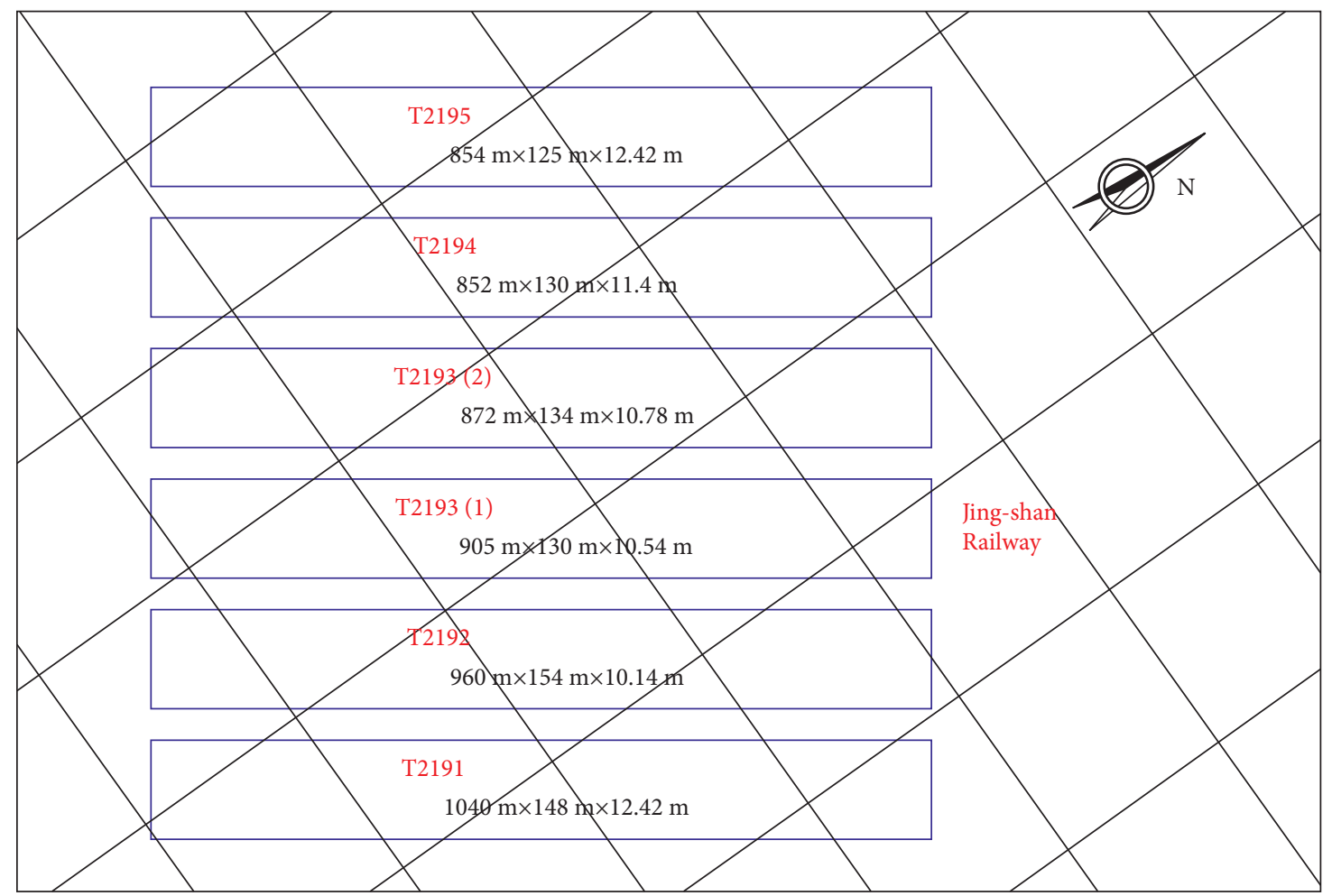

FIgURE 1: Distribution of six working mining faces in the Tier 2 area.

2.3. Separation-Zone Spatial Analysis. In general, the mining width of the strike longwall coal face is high. After the coal seam is mined, the roof rock layer will be separated and destroyed under the action of its own weight and the vertical pressure of the overlying rock. Such separation and destruction will develop layer by layer, which will make the structure of the whole overlying strata evolve and form a new overlying rock structure. The development rules and characteristics of the separation layer are an important theoretical basis for grouting to reduce subsidence, and the formation of the separation layer space is closely related to the layered structure of the coal mine sedimentary strata, the weak bonding characteristics of the layer, and the different mechanical rock properties of each rock layer [16-18].

There are two ways of separating the overlying strata in the stope: one is the use of the normal tensile separation layer, and the other is layer shear separation. The flexural rigidity of the upper and lower separation layers is different. When the flexural rigidity of the lower layer is less than that of the upper layer, the lower layer is bent first, and the upper layer has not yet been bent, and a pull-off layer will occur; when the flexural rigidity of the lower separation layer is greater than that of the upper separation layer, the two adjacent rock layers bend and deform together, resulting in shear separation, accompanied by displacement in the horizontal direction, as shown in Figures 3 and 4 [19-22].

In Figures 3 and $4, G$ is the weight and the vertical pressure of the overlying rock.

The normal tensile separation layer conforms to the tensile strength criterion:

$$
\sigma \geq C,
$$

where $\sigma$ is the tensile stress of the underlying rock layer acting on the layer, with $\sigma=\gamma h ; \gamma$ is the bulk density of the rock; $h$ is the thickness of the rock layer; and $C$ is the normal cohesive force of the layer.

Laminar shear separation conforms to the Coulomb shear strength criterion as follows:

$$
\tau=C+\sigma \tan \varphi,
$$

where $\tau$ and $\sigma$ are the shear stress and normal stress on the plane, respectively, and $\varphi$ represents the internal friction angle acting on the plane.

With two-layer equal-thickness and homogeneous composite rock beams, the maximum shear force and maximum tensile stress on the bending moment and neutral layer (i.e., layer) under its own weight are as follows:

$$
\begin{aligned}
\tau_{\max } & =\frac{3}{4} \gamma L, \\
\sigma_{\max } & =\frac{3}{4} \frac{\gamma L^{2}}{h},
\end{aligned}
$$

where $\tau_{\max }$ and $\sigma_{\max }$ are the maximum shear stress and maximum tensile stress on the cross-section of the beam, respectively; $\gamma$ is the bulk density of the rock beam; $L$ is the span of the beam; and $h$ is the height of the beam [23-26].

To explore the development characteristics of overburden strata after mining in the second mining district of the Tangshan Mine, in the strata structure (Table 1), on the basis 
TABLe 1: Table of physical and mechanical test results of rock injected with three holes in the T2191 working face of Tangshan Mine.

\begin{tabular}{|c|c|c|c|c|c|c|c|c|}
\hline $\begin{array}{l}\text { Level } \\
\text { number }\end{array}$ & Rock name & $\begin{array}{l}\text { Total thickness } \\
(\mathrm{m})\end{array}$ & $\begin{array}{l}\text { Lamination } \\
\text { thickness (m) }\end{array}$ & $\begin{array}{l}\text { Compressive } \\
\text { strength (MPa) }\end{array}$ & $\begin{array}{c}\text { Tensile } \\
\text { strength } \\
(\mathrm{MPa})\end{array}$ & $\begin{array}{c}\text { Elastic } \\
\text { modulus }\left(\times 10^{4} \mathrm{MPa}\right)\end{array}$ & $\begin{array}{l}\text { Poisson's } \\
\text { ratio }\end{array}$ & $\begin{array}{c}\text { Bulk } \\
\text { density }(\mathrm{g} / \\
\left.\mathrm{cm}^{3}\right)\end{array}$ \\
\hline & $\begin{array}{c}\text { Alluvium } \\
\text { Coreless } \\
\text { drilling }\end{array}$ & & & & & & & \\
\hline 1 & $\begin{array}{c}\text { Coarse } \\
\text { sandstone }\end{array}$ & $240-242.75$ & 2.75 & 99.2 & 3.69 & 2.3 & 0.28 & 2.474 \\
\hline 2 & Fine sand & 245.95 & 3.2 & 61.4 & 2.17 & 1.0 & 0.17 & 2.599 \\
\hline 3 & $\begin{array}{c}\text { Coarse } \\
\text { sandstone }\end{array}$ & 250.78 & 4.83 & 65.2 & 2.91 & 1.6 & 0.17 & 2.465 \\
\hline 4 & $\begin{array}{c}\text { Coarse } \\
\text { sandstone }\end{array}$ & $254.98-257.45$ & 2.47 & 63.2 & 3.06 & 1.2 & 0.23 & 2.452 \\
\hline 5 & Mudstone & 258.17 & 0.72 & 63.6 & 2.47 & 2.1 & 0.49 & 2.709 \\
\hline 6 & Siltstone & 259.40 & 1.23 & 48.3 & 1.17 & & & 2.540 \\
\hline 7 & $\begin{array}{c}\text { Coarse } \\
\text { sandstone }\end{array}$ & 264.20 & 4.8 & 97.7 & 4.22 & 1.7 & 0.18 & 2.516 \\
\hline 8 & $\begin{array}{c}\text { Coarse } \\
\text { sandstone }\end{array}$ & $265.4-273.39$ & 7.99 & 84.5 & 3.12 & 1.4 & 0.20 & 2.542 \\
\hline 9 & Siltstone & 274.80 & 1.41 & 16.1 & 1.51 & & & 2.628 \\
\hline 10 & $\begin{array}{l}\text { Medium } \\
\text { sandstone }\end{array}$ & 276.72 & 1.92 & 131.3 & 3.94 & 2.4 & 0.12 & 2.518 \\
\hline 11 & $\begin{array}{c}\text { Coarse } \\
\text { sandstone }\end{array}$ & 281.59 & 4.87 & 85.5 & 3.51 & 1.9 & 0.16 & 2.495 \\
\hline 12 & $\begin{array}{l}\text { Medium } \\
\text { sandstone }\end{array}$ & 284.00 & 2.41 & 93.4 & 5.11 & 2.0 & 0.13 & 2.672 \\
\hline 13 & $\begin{array}{c}\text { Coarse } \\
\text { sandstone }\end{array}$ & 313.54 & 29.54 & 66.0 & 2.65 & 1.4 & 0.15 & 2.477 \\
\hline 14 & Siltstone & $314.54-320.88$ & 6.34 & 62.0 & 2.17 & 1.6 & 0.09 & 2.679 \\
\hline 15 & $\begin{array}{l}\text { Medium } \\
\text { sandstone }\end{array}$ & 322.38 & 1.5 & 90.7 & 3.48 & 1.9 & 0.06 & 2.616 \\
\hline 16 & Siltstone & 323.88 & 1.5 & 80.8 & 3.03 & & & 2.631 \\
\hline 17 & $\begin{array}{l}\text { Medium } \\
\text { sandstone }\end{array}$ & $330.26-$ & 6.38 & 98.0 & 3.26 & 2.0 & 0.06 & 2.512 \\
\hline 18 & Siltstone & 333.05 & 12.79 & 49.2 & 1.84 & 1.5 & 0.12 & 2.569 \\
\hline 19 & Siltstone & $333.95-337.71$ & 3.76 & 8.3 & & & & \\
\hline 20 & $\begin{array}{c}\text { Fine } \\
\text { sandstone }\end{array}$ & 342.57 & 4.86 & 120.8 & 5.59 & 2.3 & 0.13 & 2.586 \\
\hline 21 & Siltstone & 375.13 & 32.56 & 29.7 & 1.31 & & & 2.571 \\
\hline 22 & $\begin{array}{l}\text { Medium } \\
\text { sandstone }\end{array}$ & 376.18 & 1.03 & 124.2 & 3.93 & 2.8 & 0.10 & 2.595 \\
\hline 23 & $\begin{array}{c}\text { Coarse } \\
\text { sandstone }\end{array}$ & 380.31 & 4.13 & 99.3 & 3.86 & 1.7 & 0.10 & 2.543 \\
\hline 24 & $\begin{array}{l}\text { Medium } \\
\text { sandstone }\end{array}$ & 382.61 & 2.3 & 84.1 & 2.21 & 1.2 & 0.11 & 2.595 \\
\hline 25 & $\begin{array}{l}\text { Medium } \\
\text { sandstone }\end{array}$ & 388.37 & 5.76 & 118.6 & 4.41 & 2.4 & 0.10 & 2.586 \\
\hline 26 & Siltstone & 400.10 & 11.73 & 84.4 & 3.98 & 1.9 & 0.12 & 2.617 \\
\hline 27 & $\begin{array}{l}\text { Medium } \\
\text { sandstone }\end{array}$ & 401.35 & 1.25 & 117.7 & 4.85 & 1.7 & 0.08 & 2.604 \\
\hline 28 & Siltstone & 410.98 & 9.65 & 123.9 & 15.65 & 2.0 & 0.13 & 2.653 \\
\hline 29 & Siltstone & 416.88 & 5.9 & 110.9 & 4.45 & 2.1 & 0.16 & 2.547 \\
\hline 30 & Siltstone & 430.00 & 13.12 & 95.5 & 4.90 & 1.9 & 0.07 & 2.639 \\
\hline
\end{tabular}

of in-depth analysis, using theoretical calculations and field measurements with the combination of adjacent working face research methods, the spatial distribution characteristics of the separation layer of the overlying rock roof under the condition of fully mining the working faces of the second mining district are shown in Figure 5.
The specific observation content of separation zone rocks: (1) the range of the observed longitudinal strata: the $130-350 \mathrm{~m}$ of the overburden of the coal seam roof is mined, a total of $230 \mathrm{~m}$; (2) the observation period: from the beginning of the strata to move and deform until the strata move and deform stably; and (3) observed displacement: the 


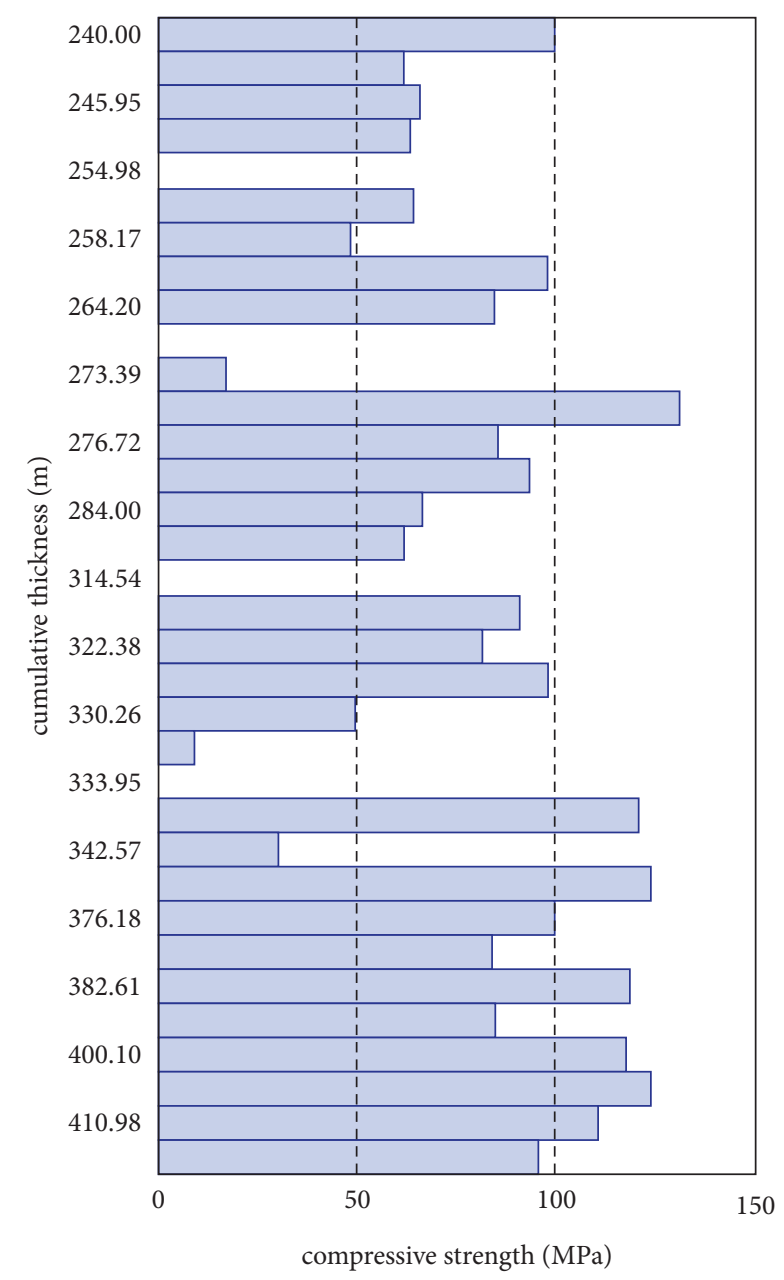

FIgURE 2: Statistical chart of the rock compressive strength of three-hole bedrock in T2191.

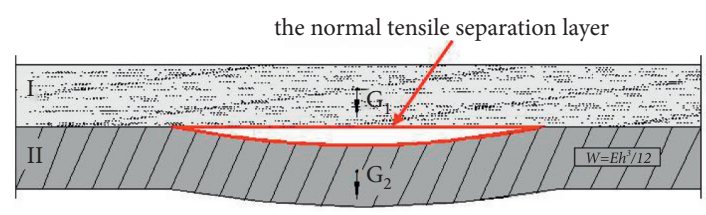

FIgURE 3: The normal tensile separation layer.

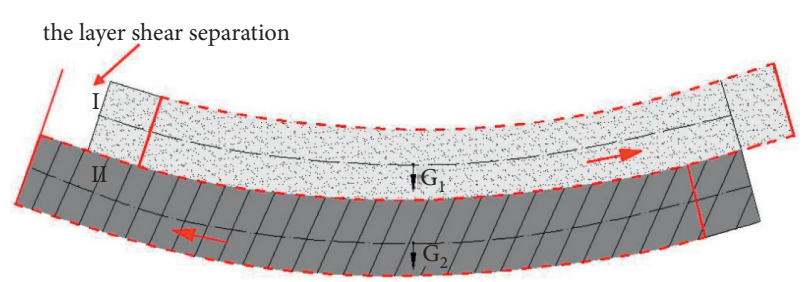

FIgURE 4: The layer shear separation.

displacement value of the rock formation along the vertical direction.

The specific observation method is as follows: (1) dig rock from the ground to move the observation borehole; (2) use compressed wood to fix the observation point of the observation horizon; (3) transmit the displacement value of a certain observation layer in the deep stratum relative to the ground to the surface through the steel wire; and (4) observe the displacement of the rock formation on the ground, using two observation methods at the same time: one is manual direct reading, and the other is the use of special monitoring instruments to automatically monitor computer storage.

After mining, the total height of the overburden caving zone and the fracture zone is approximately $191 \mathrm{~m}$. The overburden separation zone is mainly concentrated in the bedrock section within $200 \mathrm{~m}-350 \mathrm{~m}$ above 9 layers of coal. According to the on-site measurement results of adjacent working faces, during the subsidence of the overburden, the subsidence value of the measuring point and the separation value between the measuring points show regularity of gradually decreasing from bottom to top. The period of delamination formation to closure is long, and a certain amount of separation space remains above the fracture zone after the subsidence is stabilized. The maximum amount of separation in the rock formation during the subsidence period reaches $150 \mathrm{~mm}$, and the maximum separation space after the movement is stabilized is still $88 \mathrm{~mm}$.

\section{Study on Selection and Performance of Separate Layer Grouting Materials}

The selection of grouting materials and the filling performance are the key factors that affect the effect of overburden strata separation-zone grouting (OSSG). In grouting antisediment engineering, to achieve a better subsidence reduction effect, the amount of grouting must be increased as much as possible. Increasing the concentration of grouting slurry is the simplest and most economical technical method. The main problem that restricts the grouting slurry concentration is that when the slurry concentration is high, it easily precipitates, and the probability of blocking the grouting pipeline increases [27-29]. Therefore, finding or configuring a grouting liquid with a high concentration, slow sedimentation rate, and good stability is a research topic with important practical value.

According to the engineering conditions of the Tangshan Mine and the feasibility of supplying surrounding materials, fly ash and clay are selected as aggregate materials for research and analysis. The hydromechanical properties of the three ratios of the fly ash slurry, the mixed slurry of clay and fly ash, and the clay slurry, such as the sedimentation rate, are tested through experiments, and reasonable grouting is determined based on the experimental results combined with experience and theoretical knowledge of on-site grouting antisediment measures.

3.1. Material Selection. In grouting antisediment engineering, due to a large amount of grouting and the high requirements for slurry flow and cementation performance, the filling materials must be adequately supplied around the project; thus, the configuration is easy, the process is simple, and the material configuration requires high slurry concentrations and fluidity. Based on the above requirements, 


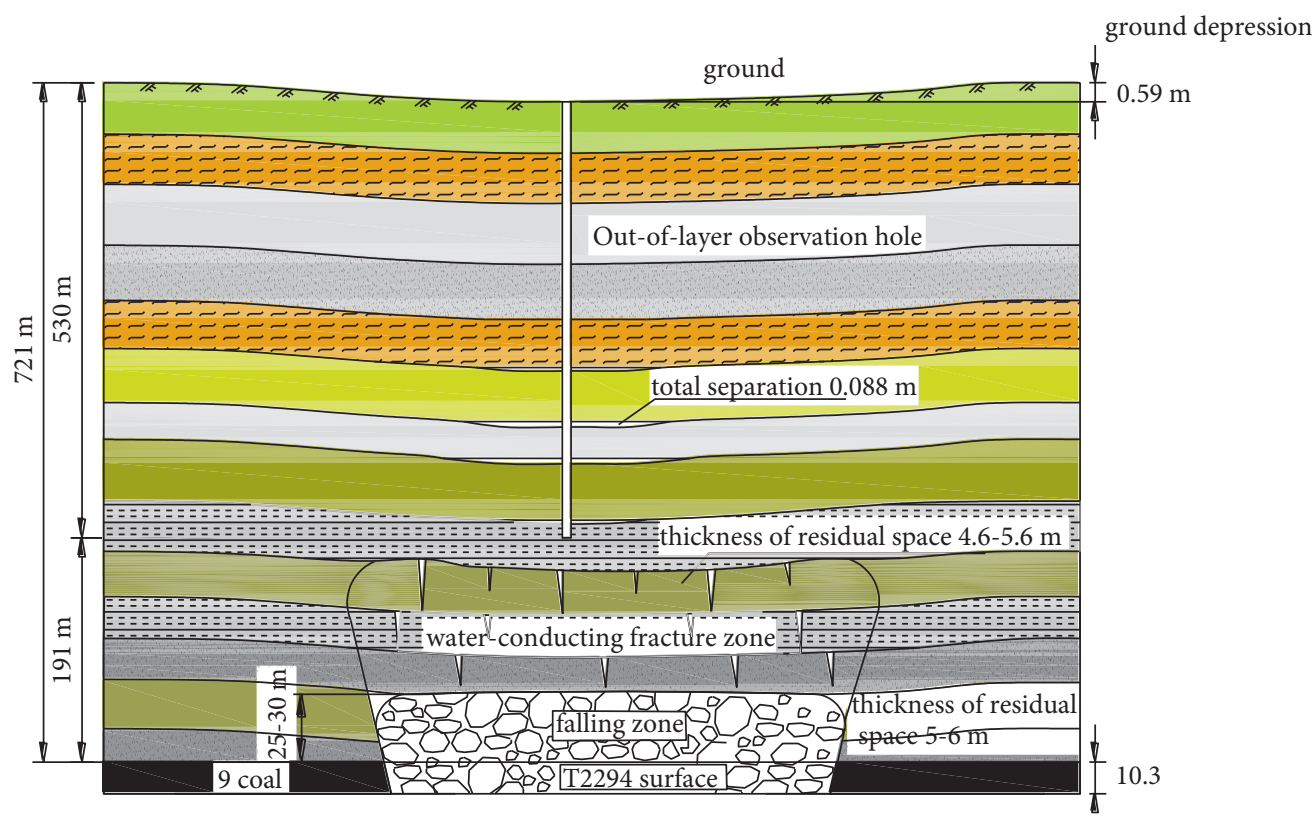

FIgURE 5: Map of the spatial distribution of overlying rock remaining after mining subsidence stability in the second mining district.

the experimental materials used the fly ash produced by the thermal power plant near Tangshan Mine and the local clay materials as two main aggregates for research.

Fly ash is a fine powder collected from the flue gas of coal-fired thermal power plant boilers. Its composition is similar to that of high-alumina clay, mainly in the state of glass; adding fly ash to the filling material can improve the strength of the filling body and replace part of the cement with fly ash. In high concentration or paste filling slurry, the presence of an appropriate amount of fly ash can reduce pipeline transportation resistance and improve the pumping performance of the paste [30-32]. There are many types of clay in nature, and the water content is an important physical state indicator that affects the engineering properties of clay. When the water content increases, it will become soft, and the bearing capacity will decrease significantly. Clay minerals have adsorptive properties, and these properties change the properties of the slurry. Clay minerals have hydrophilic properties, and many of their physical and chemical properties are related to clay mineral-water interactions. In addition, clay colloids also have rheological properties, which affect the viscosity of the colloid $[33,34]$.

After the preliminary physical performance test, the particle gradation and specific gravity of the two materials are shown in Tables 2 and 3.

\subsection{Experimental Research Purpose and Methods}

(1) Experiment purpose

Experiments are performed to determine the precipitation rate of the fly ash slurry, a mixed slurry of clay and fly ash (weight ratio of $1: 1$ ), and clay slurry and the effect of temperature on the precipitation rate. The main factors affecting the properties of the slurry are analyzed, and the experiment is equipped with a high-concentration slurry with a slow sedimentation rate, which provides a scientific basis for improving the grouting efficiency.

(2) Experimental method and process

This experiment was carried out at the Analysis and Testing Center of the School of Chemistry and Biological Engineering, Shandong University of Science and Technology. The experimental instruments included a beaker with a volume of $400 \mathrm{ml}$; a balance, weighing $1000 \mathrm{~g}$, with an accuracy of $0.1 \mathrm{~g}$; a thermometer, with a $0^{\circ} \sim 50^{\circ} \mathrm{C}$ scale and a minimum graduation value of $0.5^{\circ} \mathrm{C}$; a stopwatch; and a stirring rod.

(1) Seventy-five grams of representative clay and $300 \mathrm{~g}$ of water are measured to prepare the clay slurry; $37.5 \mathrm{~g}$ of clay, $37.5 \mathrm{~g}$ of fly ash, and $300 \mathrm{~g}$ of water are measured to prepare a mixed slurry of clay and fly ash, and $75 \mathrm{~g}$ of fly ash and $300 \mathrm{~g}$ of water are measured to prepare fly ash slurry. The prepared material is considered accurate at the $0.1 \mathrm{~g}$ level; the material is placed in a $400 \mathrm{ml}$ beaker and thoroughly stirred to completely separate the coarse and fine particles of the sample to make a suspension. The soaking time of the sample is $30-60 \mathrm{~min}$.

(2) The temperature of the suspension is recorded, and a constant temperature is maintained throughout the measurement process.

(3) The suspension forms a clear separation layer of clear water and thick slurry during the precipitation process; as the amount of the clear water gradually increases, the slurry gradually concentrates, and the separation layer gradually decreases, at which point it can be called the water slurry separation surface. 
TABLE 2: Gradation distribution of grouting Material particles.

\begin{tabular}{lcccccccccc}
\hline & $\begin{array}{c}\text { Particle diameter } \\
\text { Clay material }\end{array}$ & $\begin{array}{c}(\mathrm{mm}) \\
\end{array}$ & $>0.5$ & $0.5 \sim 0.25$ & $0.25 \sim 0.1$ & $0.1 \sim 0.075$ & $0.075 \sim 0.05$ & $0.05 \sim 0.01$ & $0.01 \sim 0.005$ & $0.005 \sim 0.002<0.002$ \\
& $\begin{array}{c}\text { Percentage (\%) } \\
\text { Fly ash }\end{array}$ & 1.1 & 1.4 & 7.2 & 1.7 & 10.0 & 42.2 & 9.7 & 6.6 & 20.1 \\
material & $\begin{array}{c}\text { Particle diameter } \\
(\mathrm{mm})\end{array}$ & $\geq 5$ & $2 \sim 5$ & $1 \sim 2$ & $0.5 \sim 1$ & $0.25 \sim 0.5$ & $0.075 \sim 0.25$ & $\leq 0.075$ & - & - \\
& Percentage (\%) & 0.218 & 2.489 & 3.066 & 9.403 & 13.127 & 53.928 & 17.769 & - & - \\
\hline
\end{tabular}

TABLE 3: Physical parameters of grouting material.

\begin{tabular}{|c|c|c|c|c|c|c|c|c|c|c|}
\hline \multirow{2}{*}{ Clay material } & $\begin{array}{l}\text { Particle diameter } \\
\qquad(\mathrm{mm})\end{array}$ & $>0.5$ & $0.5 \sim 0.25$ & $0.25 \sim 0.1$ & $0.1 \sim 0.075$ & $0.075 \sim 0.05$ & $0.05 \sim 0.01$ & $0.01 \sim 0.005$ & $0.005 \sim 0.002$ & $<0.002$ \\
\hline & Percentage (\%) & 1.1 & 1.4 & 7.2 & 1.7 & 10.0 & 42.2 & 9.7 & 6.6 & 20.1 \\
\hline \multirow{2}{*}{$\begin{array}{l}\text { Fly ash } \\
\text { material }\end{array}$} & $\begin{array}{l}\text { particle diameter } \\
(\mathrm{mm})\end{array}$ & $\geq 5$ & $2 \sim 5$ & $1 \sim 2$ & $0.5 \sim 1$ & $0.25 \sim 0.5$ & $0.075 \sim 0.25$ & $\leq 0.075$ & - & - \\
\hline & Percentage (\%) & 0.218 & 2.489 & 3.066 & 9.403 & 13.127 & 53.928 & 17.769 & - & - \\
\hline
\end{tabular}

The suspension is thoroughly stirred with a stirring rod for 2 minutes; the stopwatch is started; and the time it takes for the water slurry separation surface to drop to $30 \mathrm{~mm}, 36 \mathrm{~mm}, 42 \mathrm{~mm}, 48 \mathrm{~mm}$, and $54 \mathrm{~mm}$, as well as the limit sedimentation height and time of the sediment, is recorded. The volume weight can be directly calculated based on the measurement results with a balance, beaker, and so on. The bulk densities of the three slurries in this experiment were all $1.07 \mathrm{~g} / \mathrm{ml}$. The experimental process is shown in Figure 6. Among them, 1, 2, and 3 in the picture represent: fly ash slurry, mixed slurry of clay and fly ash, and clay slurry, respectively.

3.3. Experimental Result. The purpose of this experiment is to test the sedimentation speed and other hydrodynamic characteristics of slurries composed of different materials. The experimental results are shown in Tables 4-6. The heights of the three slurries after final precipitation are as follows: clay slurry: $15 \mathrm{~mm}$, clay and fly ash mixed slurry: $16.5 \mathrm{~mm}$, and fly ash slurry: $19 \mathrm{~mm}$.

Analyzing and summarizing the above experimental results, the relationship curve between the precipitation distance and time of different slurries at different temperatures is shown in Figure 7, and the precipitation speed change curve of the slurries at different temperatures and different aggregates is shown in Figure 8.

\section{Discussion}

(1) The precipitation rates of the mortar, lime soil, and soil slurries are significantly different. Mortar precipitation is the fastest; that of the lime soil slurry is the next fastest; and that of the soil slurry is the slowest. At $16^{\circ} \mathrm{C}$, the time required for the water slurry separation surface of the three kinds of slurry to sink to $42 \mathrm{~mm}$ is $92 \mathrm{~s}, 221 \mathrm{~s}$, and $345 \mathrm{~s}$, respectively. The precipitation time of the lime soil slurry is 2.4 times that of the mortar, and the precipitation time of the soil slurry is 3.75 times that of the mortar.
(2) Regardless of the slurry type used, the precipitation speed of the water slurry separation surface is highly sensitive to temperature. The trend follows the observation that the lower the temperature is, the slower the precipitation speed and the better the stability of the slurry. For the clay slurry, although the precipitation rate increases after the temperature reaches higher than $16^{\circ} \mathrm{C}$, the change is not particularly obvious; the mixed slurry exhibits a particularly notable change in temperature. When the temperature increases from $0^{\circ} \mathrm{C}$ to $16^{\circ} \mathrm{C}$, the precipitation rate increases by $72.7 \%$. When the temperature increases to $36^{\circ} \mathrm{C}$, the precipitation rate increases by $127.3 \%$.

(3) For the three slurries, the precipitation rate is largest at the beginning and then decreases slowly. The mixed slurry has the best stability. Before the top layer precipitates to $42 \mathrm{~mm}$, it sinks at almost a constant speed. Analysis of the reason is that after fully mixing the clay and fly ash particles, they have a higher degree of dispersion. Tiny clay particles, fly ash, and water combine to form a colloidal dispersion system so that the particles of fly ash and soil have better suspension stability.

(4) The precipitation rate of a slurry is also related to the soaking time of the aggregates. The longer the soaking time is, the smaller the precipitation rate is.

(5) The concentration of grout is one of the key parameters considered in grouting engineering. Properly increasing the slurry concentration is beneficial to increasing the grouting volume per unit time and is beneficial to supporting a large amount of grouting during the peak of the separation layer development to improve the subsidence reduction effect; it is beneficial to reduce the ineffective water injection of the grouting pump, reduce the grouting cost, and improve the economic efficiency. According to the aforementioned experimental results, when the slurry concentration is approximately $40 \%$, the bulk density is approximately 1.20 ; the 


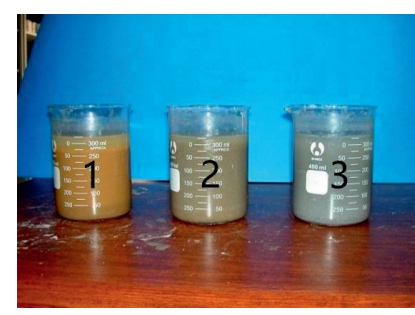

(a)

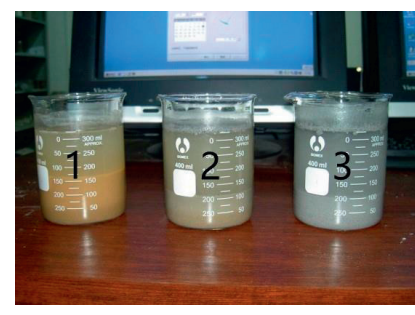

(b)

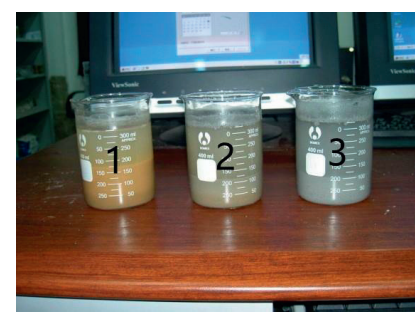

(c)

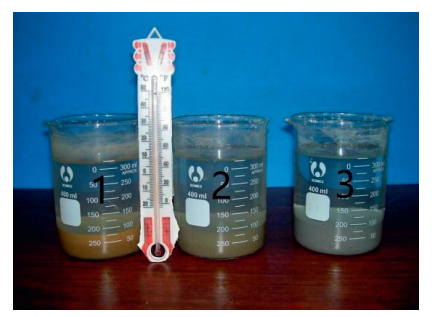

(d)

FIGURE 6: Experimental process.

Table 4: Precipitation time and speed of fly ash slurry.

\begin{tabular}{|c|c|c|c|c|c|c|}
\hline \multirow[t]{2}{*}{ Testing contents } & \multicolumn{3}{|c|}{$\begin{array}{l}\text { Precipitation time at different temperatures } \\
\text { (s) }\end{array}$} & \multicolumn{3}{|c|}{$\begin{array}{l}\text { Precipitation rate at different temperatures } \\
\qquad(\mathrm{mm} / \mathrm{s})\end{array}$} \\
\hline & $0^{\circ} \mathrm{C}$ & $16^{\circ} \mathrm{C}$ & $36^{\circ} \mathrm{C}$ & $0^{\circ} \mathrm{C}$ & $16^{\circ} \mathrm{C}$ & $36^{\circ} \mathrm{C}$ \\
\hline $30 \mathrm{~mm}$ & 92 & 63 & 42 & 0.33 & 0.48 & 0.71 \\
\hline $36 \mathrm{~mm}$ & 114 & 76 & 52 & 0.32 & 0.47 & 0.69 \\
\hline $42 \mathrm{~mm}$ & 146 & 92 & 67 & 0.29 & 0.46 & 0.63 \\
\hline $48 \mathrm{~mm}$ & 212 & 130 & 99 & 0.23 & 0.40 & 0.48 \\
\hline $54 \mathrm{~mm}$ & 571 & 295 & 218 & 0.09 & 0.18 & 0.25 \\
\hline
\end{tabular}

Remarks

The temperature at the end of the experiment is $6^{\circ} \mathrm{C}, 16^{\circ} \mathrm{C}$, and $29^{\circ} \mathrm{C}$.

TABle 5: Precipitation time and speed of mixed slurry of fly ash and clay.

\begin{tabular}{|c|c|c|c|c|c|c|}
\hline \multirow[t]{2}{*}{ Testing contents } & \multicolumn{3}{|c|}{$\begin{array}{l}\text { Precipitation time at different temperatures } \\
(\mathrm{s})\end{array}$} & \multicolumn{3}{|c|}{$\begin{array}{l}\text { Precipitation rate at different temperatures } \\
\qquad(\mathrm{mm} / \mathrm{s})\end{array}$} \\
\hline & $0^{\circ} \mathrm{C}$ & $16^{\circ} \mathrm{C}$ & $36^{\circ} \mathrm{C}$ & $0^{\circ} \mathrm{C}$ & $16^{\circ} \mathrm{C}$ & $36^{\circ} \mathrm{C}$ \\
\hline $30 \mathrm{~mm}$ & 265 & 152 & 120 & 0.11 & 0.19 & 0.25 \\
\hline $36 \mathrm{~mm}$ & 320 & 188 & 145 & 0.11 & 0.19 & 0.25 \\
\hline $42 \mathrm{~mm}$ & 380 & 221 & 175 & 0.11 & 0.19 & 0.24 \\
\hline $48 \mathrm{~mm}$ & 470 & 261 & 226 & 0.10 & 0.18 & 0.21 \\
\hline $54 \mathrm{~mm}$ & 778 & 395 & 355 & 0.07 & 0.14 & 0.1 \\
\hline
\end{tabular}

Remarks The temperature at the end of the experiment is $4{ }^{\circ} \mathrm{C}, 16^{\circ} \mathrm{C}$, and $30^{\circ} \mathrm{C}$.

TABle 6: Precipitation time and speed of clay Slurry.

\begin{tabular}{|c|c|c|c|c|c|c|}
\hline \multirow[t]{2}{*}{ Testing contents } & \multicolumn{3}{|c|}{$\begin{array}{l}\text { Precipitation time at different temperatures } \\
\text { (s) }\end{array}$} & \multicolumn{3}{|c|}{$\begin{array}{l}\text { Precipitation rate at different temperatures } \\
\qquad(\mathrm{mm} / \mathrm{s})\end{array}$} \\
\hline & $0^{\circ} \mathrm{C}$ & $16^{\circ} \mathrm{C}$ & $36^{\circ} \mathrm{C}$ & $0^{\circ} \mathrm{C}$ & $16^{\circ} \mathrm{C}$ & $36^{\circ} \mathrm{C}$ \\
\hline $30 \mathrm{~mm}$ & 312 & 228 & 205 & 0.1 & 0.13 & 0.15 \\
\hline $36 \mathrm{~mm}$ & 385 & 284 & 260 & 0.09 & 0.13 & 0.14 \\
\hline $42 \mathrm{~mm}$ & 462 & 345 & 321 & 0.09 & 0.12 & 0.131 \\
\hline $48 \mathrm{~mm}$ & 575 & 431 & 423 & 0.08 & 0.11 & 0.11 \\
\hline $54 \mathrm{~mm}$ & 860 & 652 & 744 & 0.06 & 0.08 & 0.07 \\
\hline
\end{tabular}

content of clay in the aggregate is $40-50 \%$; the temperature is above $0^{\circ} \mathrm{C}$; and the temperature is lower, so the stability and fluidity can be better unified.

\section{Practical Application of OSSG}

5.1. Grouting Plan Design. The mining depth of the Tangshan second mining district is $600-700 \mathrm{~m}$; the bedrock thickness is approximately $200 \mathrm{~m}$; the overburden is a medium-hard stratum with alternating hard and soft; and the mining thickness is approximately $10 \mathrm{~m}$, so it provides good strata conditions for multilayer overburden separation grouting to reduce settlement. According to the analysis of the overlying rock structure in the second mining district and the on-site engineering detection of the separation zone, it was decided to use continuous grouting technology with the characteristics of multiple separation zones within the full height section, large flow, and high concentration to carry out overlying separation layer grouting in the second 


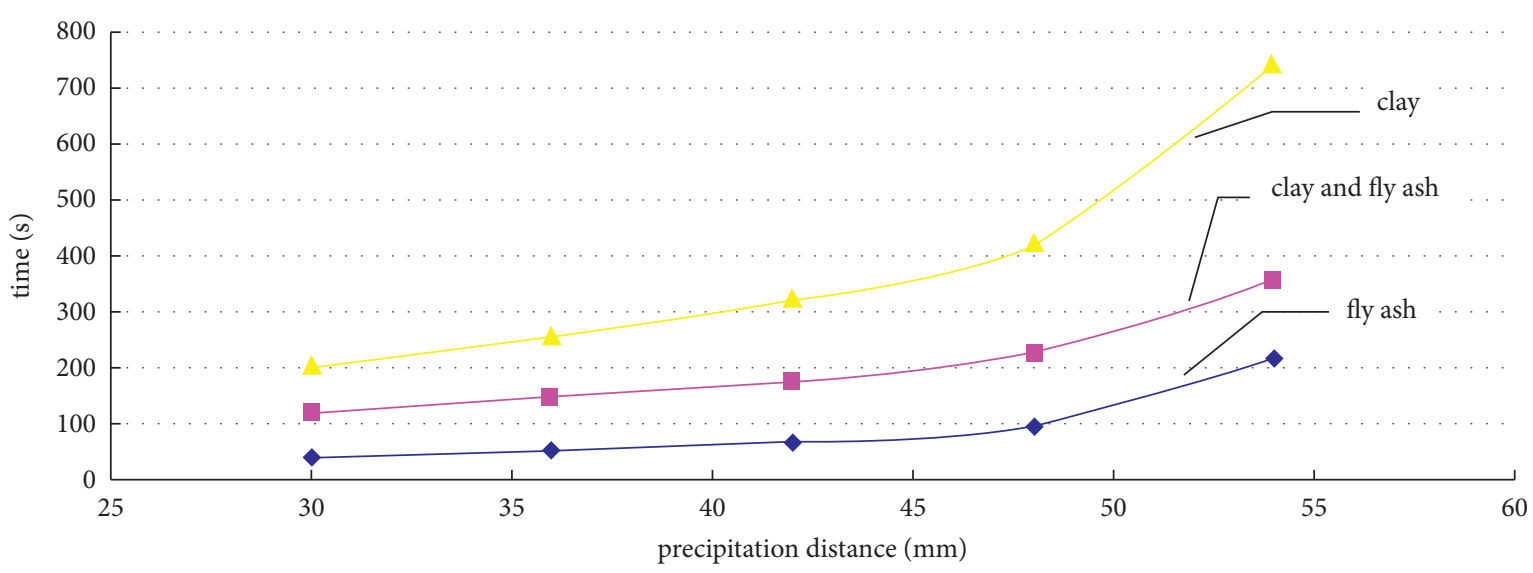

(a)

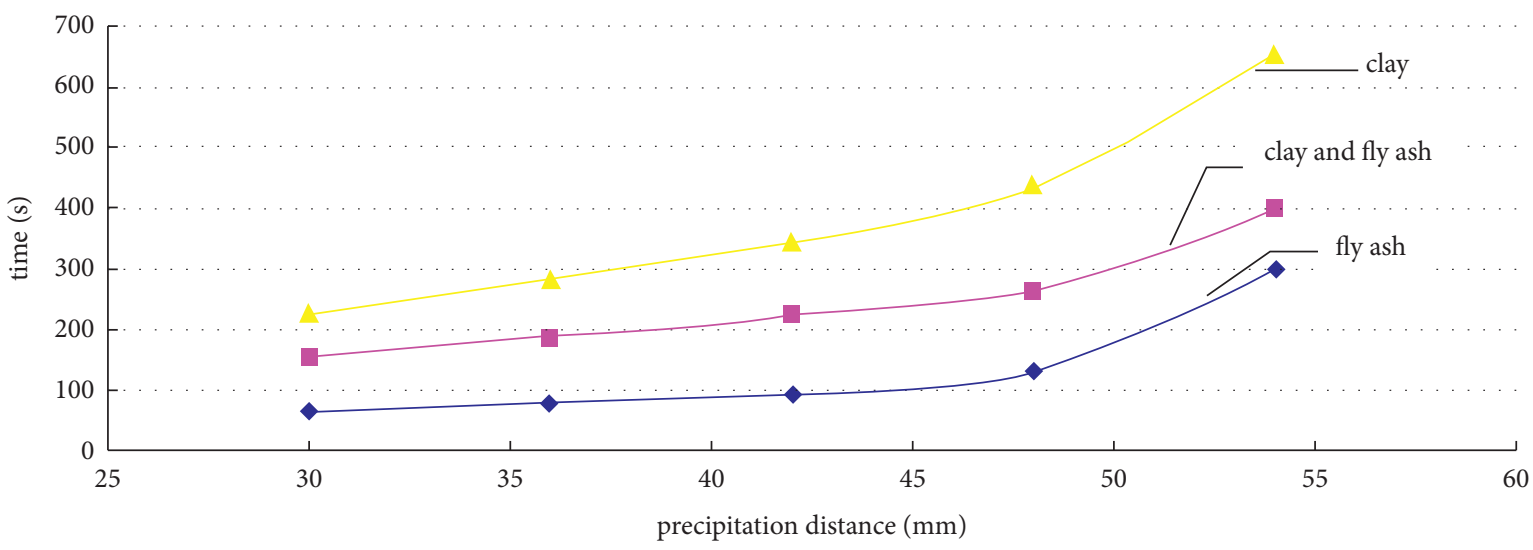

(b)

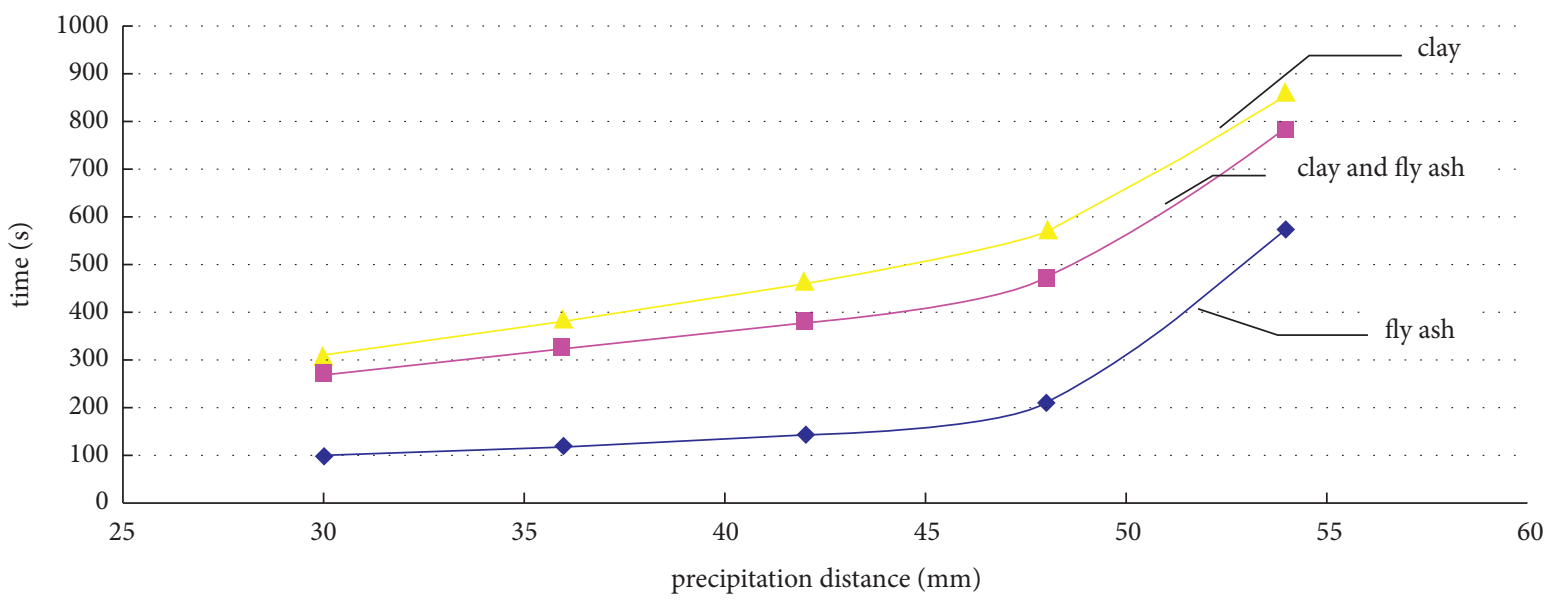

(c)

FIGURE 7: The relationship curve of the precipitation distance and time of different slurries at different temperatures: (a) the relationship between precipitation distance and time for different slurries at $36^{\circ} \mathrm{C}$, (b) the relationship between precipitation distance and time for different slurries at $16^{\circ} \mathrm{C}$, and (c) the relationship between precipitation distance and time for different slurries at $0^{\circ} \mathrm{C}$.

mining district. The so-called multiple separation zones within full-height section grouting mean that one grouting borehole penetrates multiple separation layers in the separation zone and is designed to guide all the separation layers throughout the entire bedrock above the water fracture zone structure at the same time. The so-called large flow and high concentration increase the capacity of the grouting pump of the surface grouting station and maximize the grouting volume per unit time during the negative pressure and ground pressure grouting stage; at the same time, the grouting slurry concentration is increased. At the same time, the concentration of the grouting slurry is increased from the bulk density of the slurry at the initial stage of grouting from 1.145 to 1.155 and at the later stage of grouting to the 


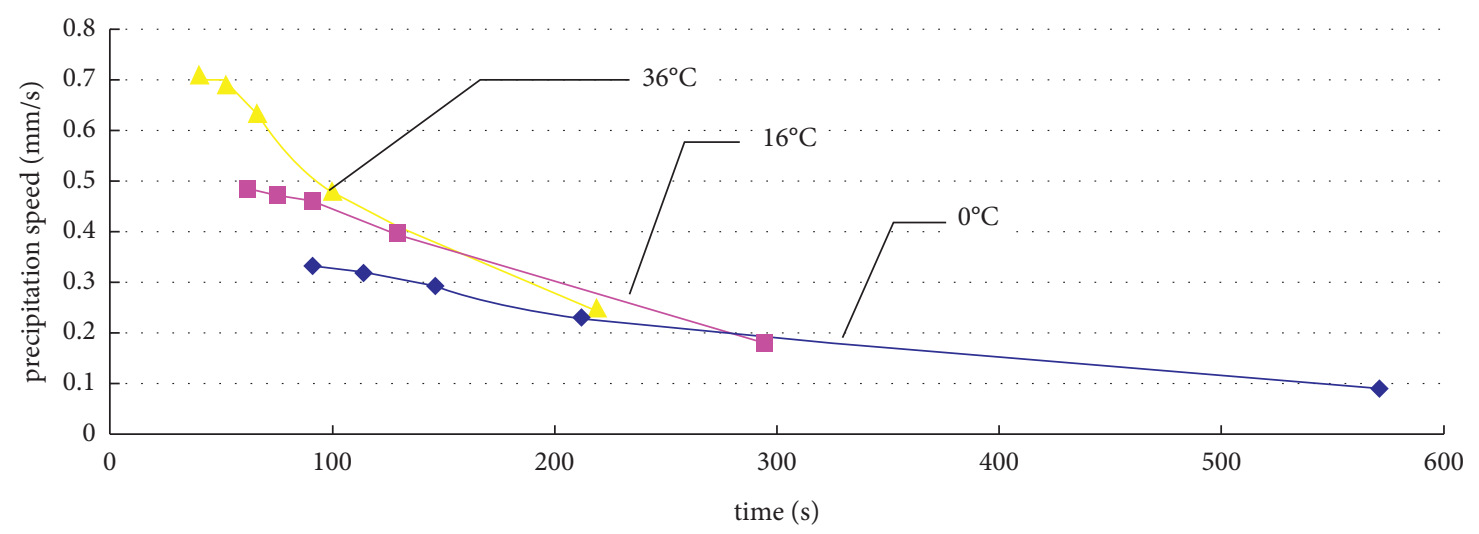

(a)

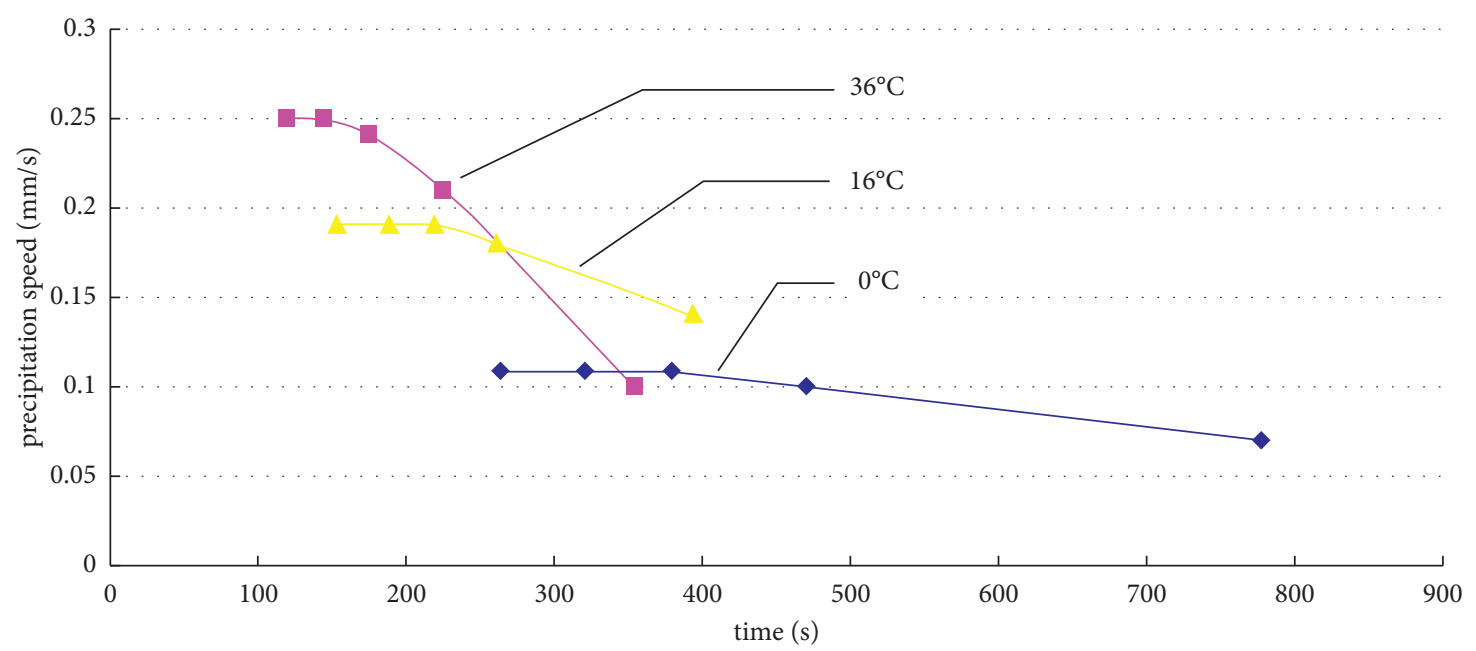

(b)

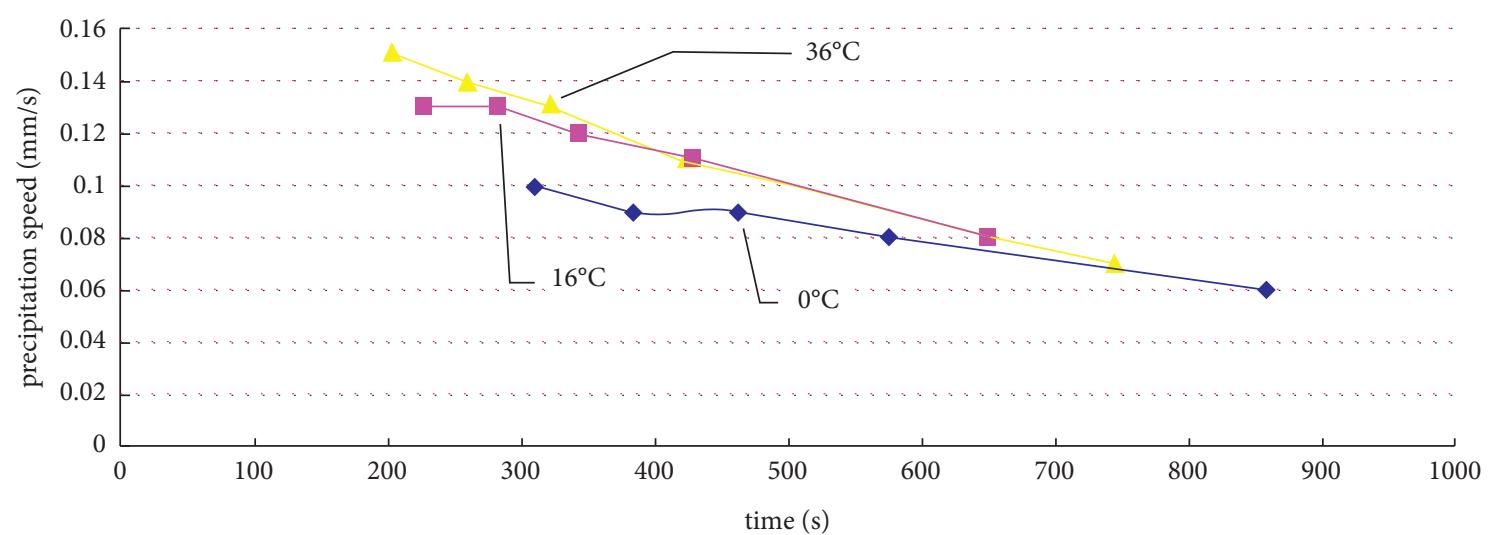

(c)

Figure 8: Precipitation speed change curve of the slurries at different temperatures and different aggregates: (a) variation curve of precipitation rate of fly ash slurry under different temperature conditions, (b) variation curve of mixed slurry precipitation speed at the same temperature, and (c) variation curve of clay slurry precipitation rate at different temperatures.

current 1.19 to 1.24 . The so-called continuous grouting mechanism, on the one hand, is the implemented grouting process, in which the pump is no longer regularly stopped to flush the pipelines and boreholes, and on the other hand, it improves the reliability of the power supply, grouting pump, pipeline, and slurry supply system and adopts multiple position grouting technology realizes long-term continuous operation of grouting construction.

According to the occurrence of coal strata in the mining district and the analysis of the law of subsidence movement in the mining of overlying rocks, while comprehensively considering the size of the grouting range and the need to 
increase the amount of grouting and reduce the amount of drilling as much as possible, the layout plan of the grouting boreholes in the six working faces of the second mining district is shown in Figure 9.

According to the spatial distribution characteristics of the overlying strata in the second mining district, considering the needs of continuous grouting technology with the characteristics of multiple separation zones within the full height section, with a large flow and a high concentration, the grouting boreholes of the six grouting working faces adopt the same structure. As shown in Figure 10, it is divided into three sections from top to bottom: (1) loose layer cementing section; (2) bedrock steel pipe wall protection section; and (3) flower tube wall protection grouting section.

5.2. Grouting System and Process. The overburden separation grouting process mainly includes mortar preparation, pressurization, transportation, and injection. The formed grouting system is shown in Figure 11. The core ideas behind the grouting process are to use a reasonable process method, make full use of the existing equipment, adjust the grouting parameters according to the change of the grouting pressure, and achieve continuous grouting with a large flow and a high concentration to maximize the amount of injected ash [35-38].

\section{(1) Grouting system}

The slurry supply system mainly includes the following components: the belt conveyor, which transports fly ash and clay materials out of the ash pit and puts them into the mixing tank; the fly ash slurry, which is transported from the thermal power plant through the pipeline and is first injected into the shunt bucket and then into the mixing tank; the mortar, which is adjusted according to the grouting requirements in the mixing tank; and then the large particles (particle diameter greater than $3 \mathrm{~mm}$ ), which are removed through a vibrating screen and then moved into the slurry storage mixing tank in the pumping station building.

The booster pump station is composed of a mediumpressure pump, a high-pressure pump, a slurry mixing tank, and a voltage stabilizing device. There are seven medium-pressure pumps in the pumping station: four of them are TBW-1200/7B mediumpressure pumps with a pressure of $7 \mathrm{MPa}$ and a slurry capacity of $72 \mathrm{~m}^{3} / \mathrm{h}$; three of them are TBW-850/50B medium-pressure pumps with a pressure of $5 \mathrm{MPa}$ and a slurry capacity of $51 \mathrm{~m}^{3} / \mathrm{h}$; and two of them are high-pressure pumps with a pressure of 5-21 MPa and a slurry capacity of $10-50 \mathrm{~m}^{3} / \mathrm{h}$; There are three slurry pipelines: two $114 \times 7.37$ pipelines and one $140 \times 7.72$ pipeline. The length of the pipeline from the grouting station to the grouting borehole is approximately $1500 \mathrm{~m}-2000 \mathrm{~m}$.

(2) Grouting technique

When preparing the mortar, the appropriate amount of fly ash and clay is added to the mortar from the power plant and mixed in the mixing tank to produce a concentration that meets the requirements of grouting. The higher the slurry concentration, the greater the amount of ash injected and the higher the grouting efficiency. Every time the slurry bulk density increases by $0.01 \mathrm{t} / \mathrm{m}^{3}$, the injection-production ratio increases by $1.59 \%$. During the grouting process, it is necessary to accurately monitor the bulk density of the mortar to maintain a proper bulk density value, especially in the negative pressure grouting stage. To achieve large flow and high concentration grouting, the bulk density of the grout can be controlled between 1.17 and 1.20, and the bulk density of the slurry in the pressure grouting stage is between 1.14 and 1.17. During the preparation of the mortar, attention should be given to screening out coke ballast with a particle size of more than $3 \mathrm{~mm}$ to reduce its wear on the grouting pump; in the stage of negative pressure and low pressure (pump pressure less than 1.0 MPa), the bulk density of the grouting liquid should be increased as much as possible.

According to past experience, after the working face is pushed through the borehole at 10-30 m, the overlying strata will be separated and grouted. When the underground working face is pushed to the bottom of the grouting borehole, a clean water pressure test is carried out every day; the separation layer is found in time; and grouting is carried out in time.

The grouting pressure has a linear relationship with the square of the grouting volume and increases with time; the stronger the permeability of the rock formation and the higher the porosity, the lower the grouting pressure. According to the capacity of the existing medium-pressure grouting pump, the maximum grouting pressure is designed to be $5 \mathrm{MPa}$.

Maintaining the continuity of grouting and simultaneous grouting at multiple layers of the separation zone are two key technologies that can be implemented to increase the grouting volume. Continuous grouting can avoid hole blockage and prolong the closure time of the separation zone. To this end, it should be fully guaranteed from multiple aspects, such as power supply (dual power supply), equipment, and labor organization, and various engineering faults should be eliminated with sufficient time.

5.3. Analysis of Ground Subsidence Effect. A total of $7,132,839 \mathrm{~m}^{3}$ of grouting is grouted in the six mining working faces of the second zone. Among them, the upper working face T2193 with the largest amount of grouting is injected with a total of $1,721,462 \mathrm{~m}^{3}$ of fly ash slurry. The injection-production ratio of the second mining district is $24.2 \%$; the grouting ratio is $100.3 \%$; and the subsidence reduction rate is $51.5 \%$. The injection-production ratio and subsidence reduction rate of each working face in the second mining district are shown in Tables 7 and 8.

To observe the ground subsidence that occurs after the mining of the railway coal pillars in a timely and accurate 


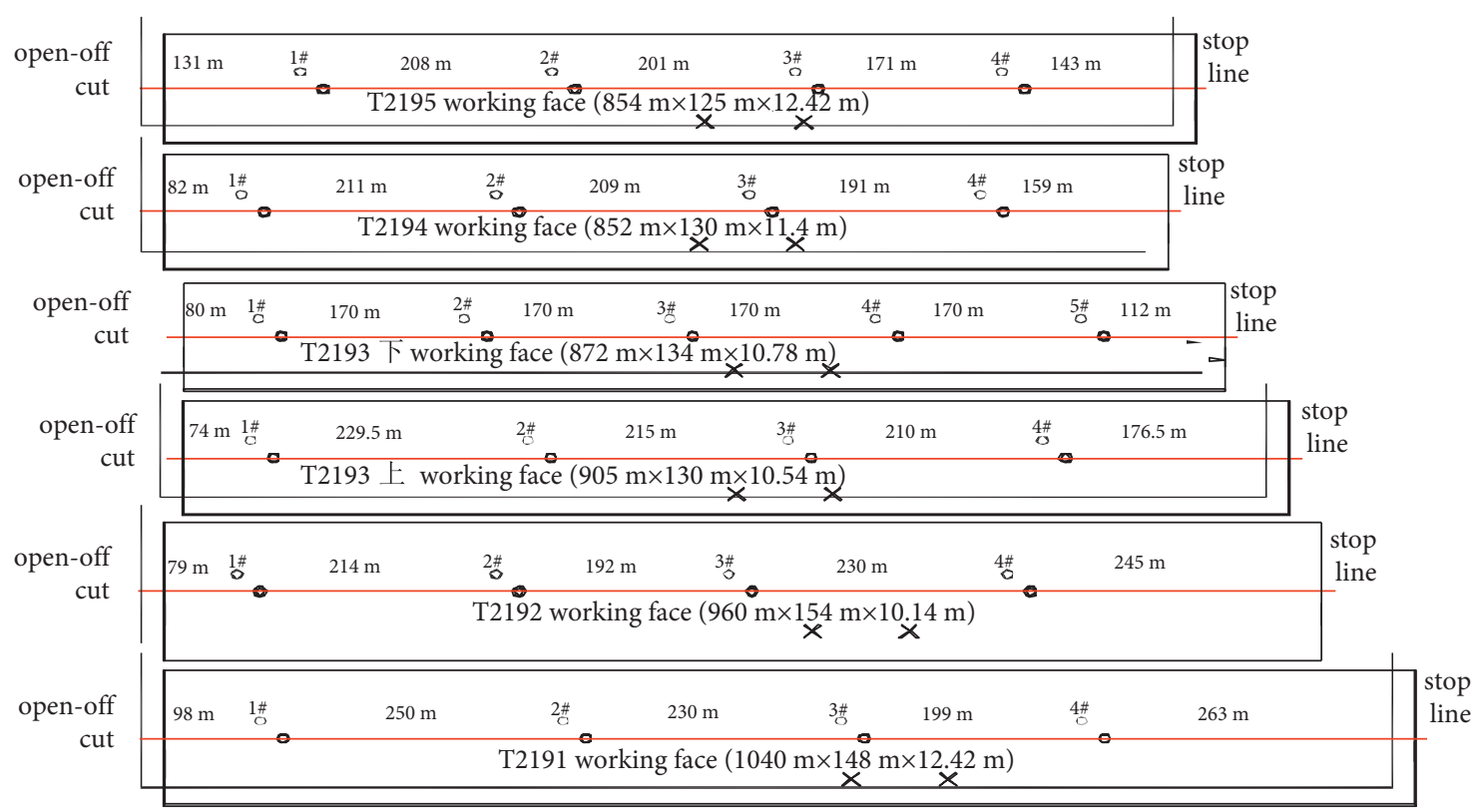

Figure 9: Schematic diagram of borehole layout in the second mining district.

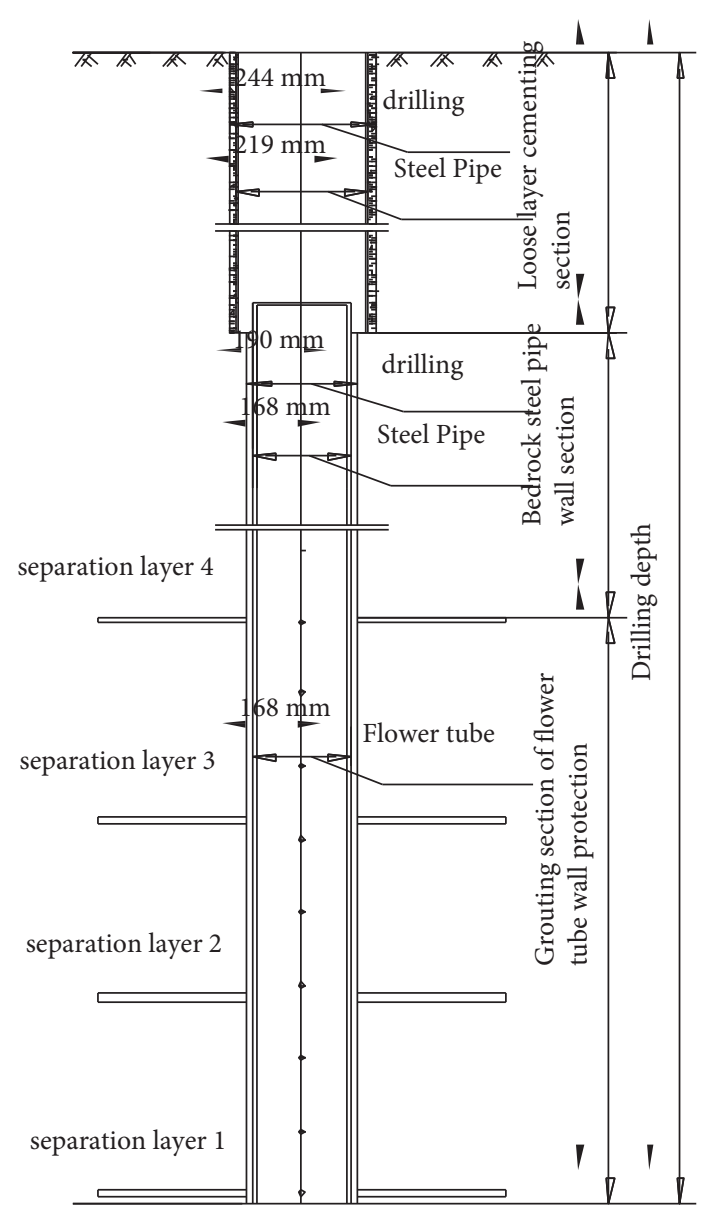

FIGURE 10: Schematic diagram of the grouting borehole structure of each fully mechanized caving face in the second mining district. manner, during the construction of the overlying strata grouting project in the second mining district, a total of five rock movement observation lines (one above each working face) are arranged on the ground corresponding to the working face to monitor the effect of ground surface subsidence. The typical monitored ground surface subsidence curves are shown in Figure 12.

\subsection{Application Effect and Discussion}

(1) Application effect analysis

According to the analysis of on-site engineering application effects, using overlying strata separation layer grouting to implement fully mechanized caving mining of the original Jingshan railway coal pillars, considering the overburden separation zone formed by mining to fill fly ash slurry, can reduce ground subsidence. The overlying rock grouting subsidence reduction rate in the second mining district of the Kailuan Tangshan coal mine under fully mined conditions exceeds 50\%. After proper maintenance, safe railway transportation can be achieved, with low ground surface impact, reducing ground building removal and land damage. Underground mining with fully mechanized caving can not only effectively extract coal resources with a high recovery rate but also effectively prevent rock bursts that would restrict the completion of safe mining, the improvement of the economic benefits of enterprises, and the extension of the life of the mine. 


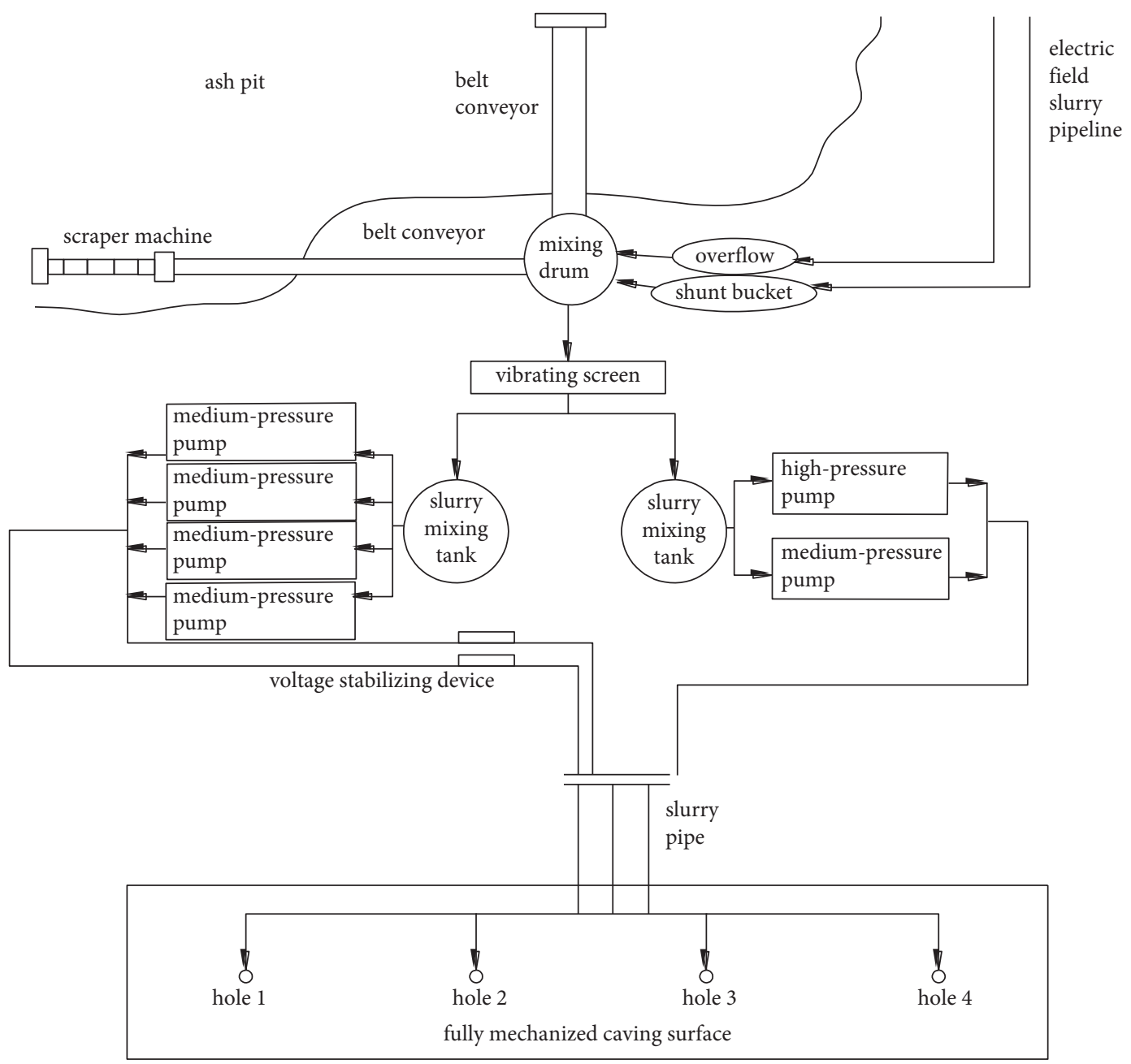

FIGURE 11: Schematic diagram of grouting system.

TABLE 7: The injection-production ratio table of each side of the second mining district.

\begin{tabular}{lccccccc}
\hline & T2191 & T2192 & T2193上 & T2193下 & T2194 & T2195 & Second mining district \\
\hline Mining space $\left(\mathrm{m}^{3}\right)$ & $1,601,228.5$ & $1,185,036.6$ & $1,093,955.3$ & $1,044,856.0$ & $1,118,089.0$ & $1,066,103.9$ & $7,109,269.4$ \\
Grout amount $\left(\mathrm{m}^{3}\right)$ & $1,300,139$ & $1,152,108$ & $1,009,252$ & $1,223,743$ & $1,314,813$ & $1,132,784$ & $7,132,839$ \\
Cement take $\left(\mathrm{m}^{3}\right)$ & 288,075 & $257,113.6$ & $311,363.7$ & 323,597 & $290,882.2$ & 250,430 & $1,721,462$ \\
Injection ash ratio (\%) & 18 & 21.7 & 28.5 & 31 & 26 & 23.5 & 24.2 \\
Grouting ratio (\%) & 81.2 & 97.2 & 92.3 & 117.1 & 117.6 & 106.3 & 100.3 \\
\hline
\end{tabular}

TABLE 8: Calculation table of the subsidence reduction rate in the second mining district.

\begin{tabular}{lcccccc}
\hline & T2191 & T2192 & T2193 上 & T2193下 & T2194 & T2195 Second mining \\
district
\end{tabular}

(2) Insufficiency and applicable conditions

In the overburden strata separation-zone grouting technology, the precise detection of separation space and the performance and technology of grouting materials are two key issues. The current research has basically accurately found the position of separationzone spatial according to the stratigraphic conditions of the Tangshan Mine, but the detection of separation-zone spatial has not yet reached the accuracy level; At the same time, in the research of grouting 


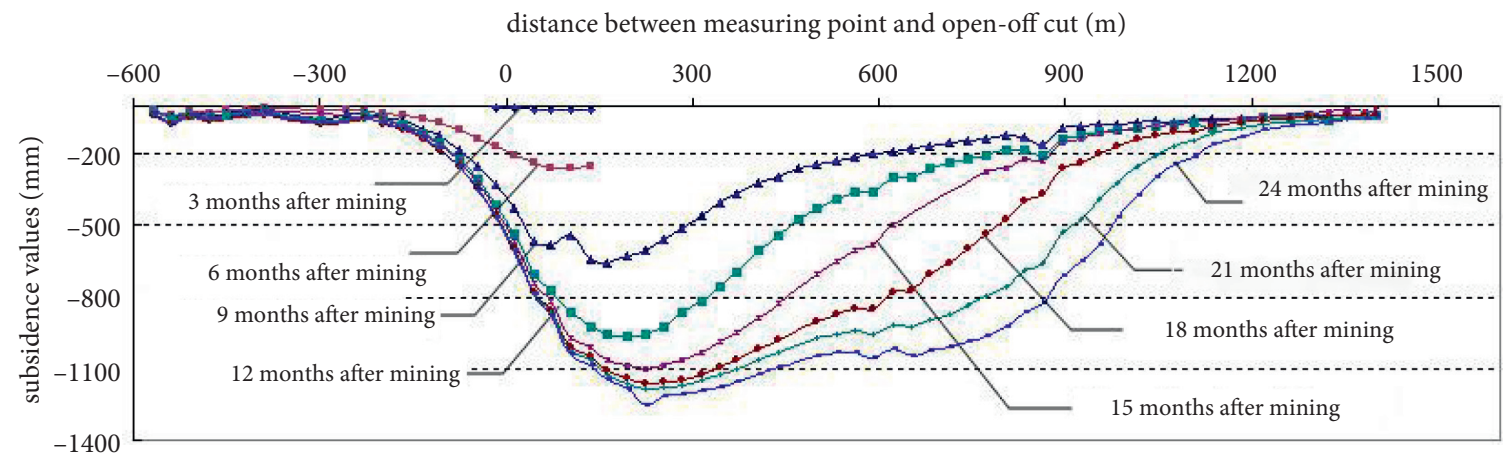

Curve of surface subsidence measured on surface T2191

(a)

distance between measuring point and open-off cut (m)

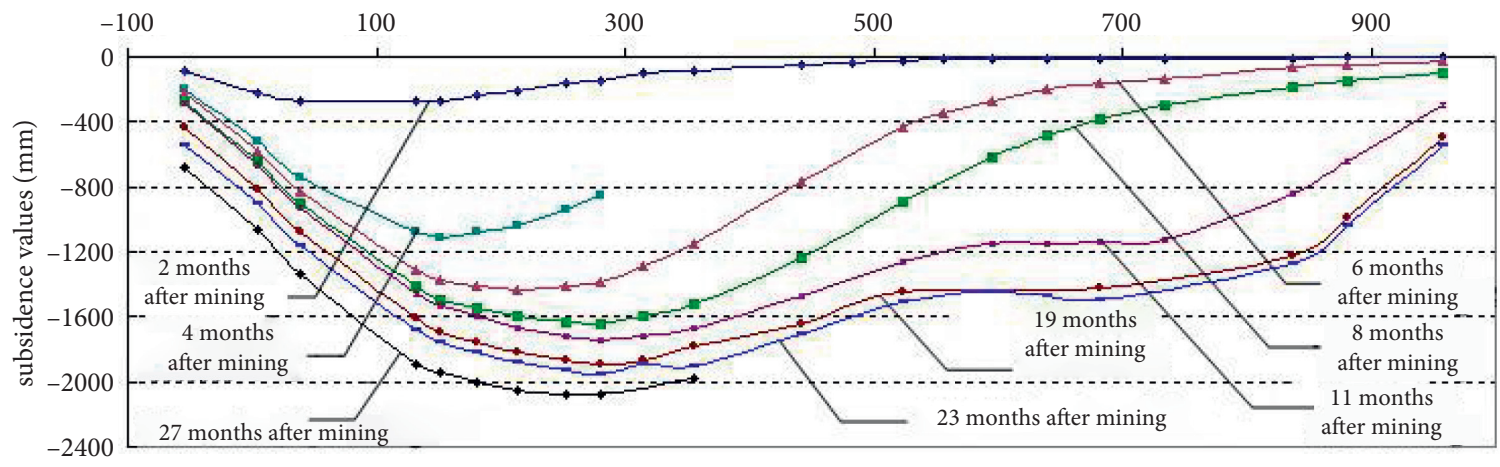

The measured surface subsidence curve of the T2192 surface

(b)

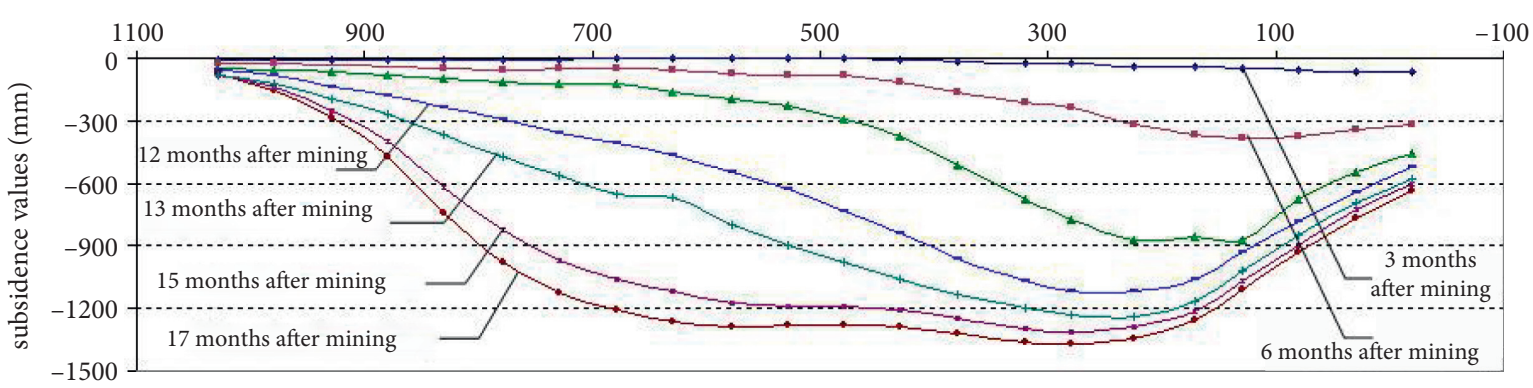

Curve of surface subsidence measured on surface T2193

(c)

distance between measuring point and open-off cut (m)

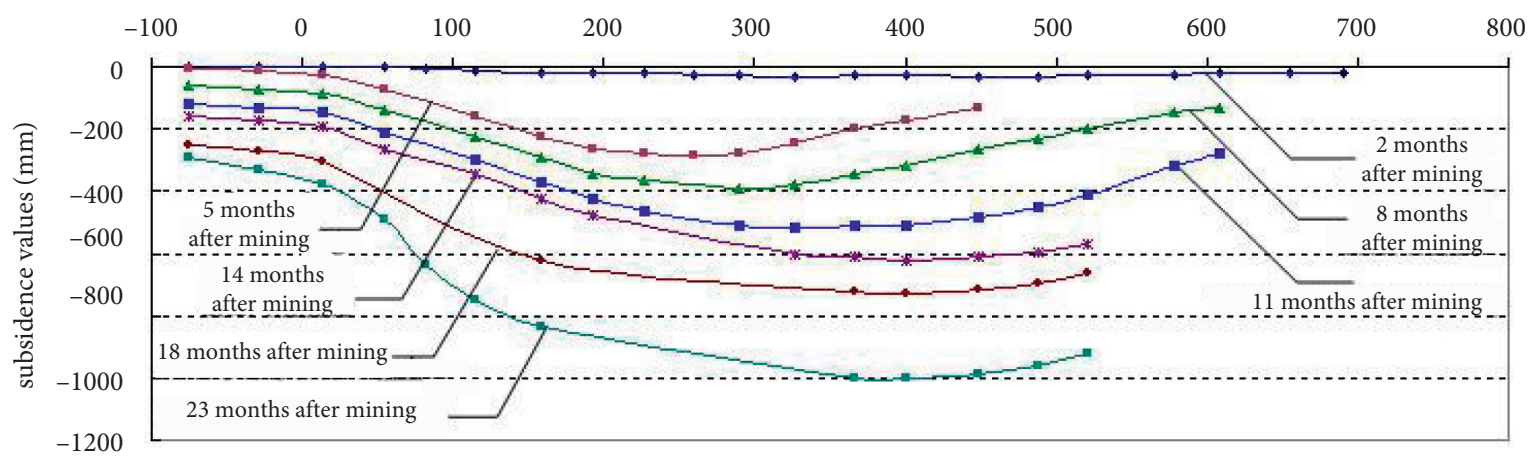

Surface subsidence curve after T2194 surface grouting

(d)

Figure 12: Continued. 


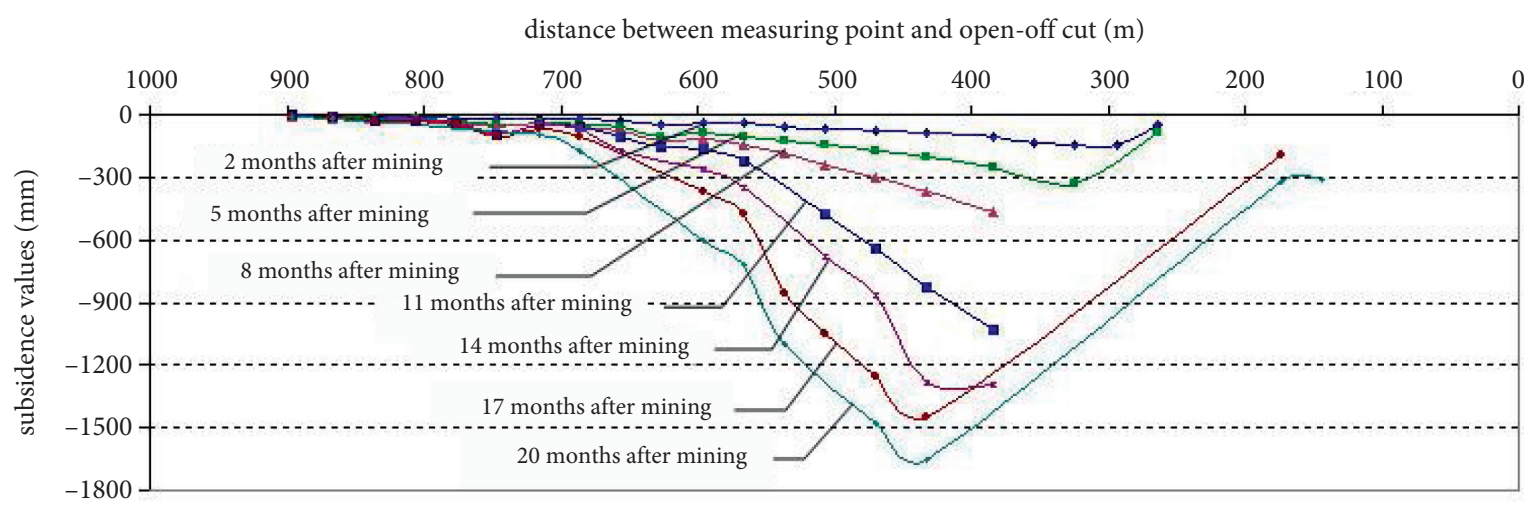

Curve of surface subsidence measured on surface T2195

(e)

Figure 12: The typical monitored ground surface subsidence curves.

materials, only the physical properties of the grout itself, such as fluidity, concentration, and so on, are involved. However, its mechanical properties after entering the separation space and solidified have not been studied in depth. This is also the next research direction.

On the whole, this technology is more suitable for the case where the normal separation caused by mining in the middle and shallow stratum is relatively developed, and it can achieve a better subsidence reduction effect.

\section{Main Conclusion}

The technology of overburden strata separation-zone grouting (OSSG) can not only effectively slow down ground subsidence and reduce damage to ground buildings and land but also inject a large amount of coal ash discharged from power plants into the ground, which is beneficial to reduce the cost of land acquisition for power plants and can provide considering economic and social benefits to mining enterprises. This technology is highly applicable to the efficient and safe mining of coal under the railway in the Tangshan coal mine.

Based on the mining range of the six working faces in the second mining district of the Tangshan Mine, the structure and mechanical parameters of the overlying rock are analyzed to determine the movement characteristics and laws of the overlying rock roof. Based on the on-site measurement of adjacent mining districts, the spatial distribution characteristics of the overlying strata roof under the condition of full mining in the second mining district were obtained, which laid the foundation for the subject research.

With fly ash and clay as the main aggregates, the focus of this study is on the selection ratio of grouting materials and the hydrodynamic properties of different slurries. The study found that when the slurry concentration is approximately $40 \%$, the bulk density is approximately 1.20 , the content of clay in the aggregate is $40-50 \%$, and the temperature is above $0^{\circ} \mathrm{C}$; when the temperature is lower, the grouting slurry is stable, and fluidity can be better unified.

According to the actual geology and mining conditions of the second mining district of the Tangshan Mine, whole section processing utilizing continuous grouting technology with the characteristics of multiple separation zones within the full height section, large flow, and high concentration is designed to carry out overburden separation layer grouting in the second mining district, forming a perfect grouting system with a reasonable grouting process. After field engineering verification, the technology achieved a $51.5 \%$ ground subsidence reduction rate, and the effect was very satisfactory, ensuring the safe and efficient mining of highquality thick coal seams under the railway and creating huge economic and social benefits for the enterprise.

\section{Data Availability}

Data used for calculation in this paper can be obtained from the corresponding author upon request.

\section{Conflicts of Interest}

The authors declare that there are no conflicts of interest.

\section{Acknowledgments}

This study was supported by the National Natural Science Foundation of China (no. 51774195), the Open Fund by State Key Laboratory of Coal Mining and Clean Utilization (no. 2021-KFYB-020), the Key Research and Development Program of Shandong Province (no. 2018GSF117023), and SDUST Research Fund.

\section{References}

[1] S. Dong, S. Samsonov, H. Yin, S. Yao, and C. Xu, "Spatiotemporal analysis of ground subsidence due to underground coal mining in Huainan coalfield, China," Environmental Earth Sciences, vol. 73, no. 9, pp. 5523-5534, 2015.

[2] J. M. Xu, W. B. Zhu, J. L. Xu, J. Y. Wu, and Y. C. Li, "Highintensity longwall mining-induced ground subsidence in 
Shendong coalfield, China," International Journal of Rock Mechanics and Mining Sciences, vol. 141, 2021.

[3] G. Marino, A. Osouli, M. Elgendy, and M. Karimpour, "Utilization of historical subsidence data for prediction of adverse subsidence conditions over trona mine," International Journal of Geomechanics, vol. 17, no. 2, 2017.

[4] Y. Yu, L. Ma, and D. Zhang, "Characteristics of roof ground subsidence while applying a continuous excavation continuous backfill method in longwall mining," Energies, vol. 13, no. 1 , p. $95,2020$.

[5] D. Xuan and J. Xu, "Longwall surface subsidence control by technology of isolated overburden grout injection," International Journal of Mining Science and Technology, vol. 27, no. 5, pp. 813-818, 2017.

[6] W. Liu, J. Xu, W. Zhu, and S. Wang, "A novel short-wall caving zone backfilling technique for controlling mining subsidence," Energy Science \& Engineering, vol. 7, no. 5, pp. 2124-2137, 2019.

[7] B. Shen and B. Poulsen, "Investigation of overburden behaviour for grout injection to control mine subsidence," International Journal of Mining Science and Technology, vol. 24, no. 3, pp. 317-323, 2014.

[8] V. Palchik, "Experimental investigation of apertures of mining-induced horizontal fractures," International Journal of Rock Mechanics and Mining Sciences, vol. 47, no. 3, pp. 502-508, 2010.

[9] V. Palchik, "Analysis of main factors influencing the apertures of mining-induced horizontal fractures at longwall coal mining," Geomech Geophys Geo, vol. 6, no. 2, 2020.

[10] D. Yin, S. Chen, B. Li, and W. Guo, "Bed separation backfill to reduce surface cracking due to mining under thick and hard conglomerate: a case study," Royal Society Open Science, vol. 6, no. 8, p. 190880, 2019.

[11] D. Xuan and J. Xu, "Grout injection into bed separation to control surface subsidence during longwall mining under villages: case study of Liudian coal mine, China," Natural Hazards, vol. 73, no. 2, pp. 883-906, 2014.

[12] D. Xuan, J. Xu, B. Wang, and H. Teng, "Borehole investigation of the effectiveness of grout injection technology on coal mine subsidence control," Rock Mechanics and Rock Engineering, vol. 48, no. 6, pp. 2435-2445, 2015.

[13] W. P. Huang, C. Li, L. W. Zhang, Q. Yuan, Y. S. Zheng, and Y. Liu, "In situ identification of water-permeable fractured zone in overlying composite strata," International Journal of Rock Mechanics and Mining Sciences, vol. 105, pp. 85-97, 2018.

[14] D. Jiang, X. Cheng, H. Luan, T. Wang, M. Zhang, and R. Hao, "Experimental investigation on the law of grout diffusion in fractured porous rock mass and its application," Processes, vol. 6, no. 10, p. 191, 2018.

[15] J. Y. Rafi and H. Stille, "Basic mechanism of elastic jacking and impact of fracture aperture change on grout spread, transmissivity and penetrability," Tunnelling and Underground Space Technology, vol. 49, pp. 174-187, 2015.

[16] J.-h. He, W.-p. Li, and W. Qiao, "A rock mechanics calculation model for identifying bed separation position and analyzing overburden breakage in mining," Arabian Journal of Geosciences, vol. 13, no. 18, 2020.

[17] V. Palchik, "Formation of fractured zones in overburden due to longwall mining," Environmental Geology, vol. 44, no. 1, pp. 28-38, 2003.

[18] W. Huang, X. Wang, Y. Shen, F. Feng, K. Wu, and C. Li, "Application of concrete-filled steel tubular columns in gobside entry retaining under thick and hard roof stratum: a case study," Energy Science \& Engineering, vol. 7, no. 6, pp. 2540-2553, 2019.

[19] J. Q. Jiang, P. Wang, Q. L. Wu, and P. P. Zhang, "Evolution laws and prediction of separated stratum space under overlying high-position magmatic rocks," Chinese Journal of Geotechnical Engineering, vol. 37, no. 10, pp. 1769-1779, 2015.

[20] X. Zhang, W. Qiao, L. J. Lei, F. S. Zeng, H. Zhang, and Y. Z. Wang, "Formation mechanism of overburden bed separation in fully mechanized top-coal caving," Journal of China Coal Society, vol. 41, no. S2, pp. 342-349, 2016.

[21] Z. Q. Song, Practical Ground Pressure Control, China University of Mining and Technology Press, Xuzhou, 1988.

[22] S. H. Wang, Y. F. Gao, and Z. L. Fu, "Study on classifying and mechanics mechnisim of grouting overlying bed-separations developing," Acta Mechanica Solida Sinica, vol. 27, pp. 164-168, 2006.

[23] F. Feng, S. J. Chen, Y. J. Wang, and W. P. Huang, "Cracking mechanism and strength criteria evaluation of granite affected by intermediate principal stresses subjected to unloading stress state," Int J Rock Mech Min, vol. 143, no. 5, Article ID 104783, 2021.

[24] W. J. Yu, G. S. Wu, B. Pan, Q. H. Wu, and Z. Liao, "Experimental investigation of the mechanical properties of sandstone-coal-bolt specimens with different angles under conventional triaxial compression," International Journal of Geomechanics, vol. 21, Article ID 04021067, 2021.

[25] W. Yu, K. Li, Z. Liu, B. An, P. Wang, and H. Wu, "Mechanical characteristics and deformation control of surrounding rock in weakly cemented siltstone," Environmental Earth Sciences, vol. 80, no. 9, pp. 1-15, 2021.

[26] W. Yu and K. Li, "Deformation mechanism and control technology of surrounding rock in the deep-buried large-span chamber," Geofluids, vol. 2020, no. 5, pp. 1-22, 2020.

[27] Y. L. Feng, L. Liang, L. H. Duan, and J. L. Li, "Researching on grouting material in Chensilou coal mine," Materials Research Innovations, vol. 19, no. S5, pp. 454-457, 2015.

[28] L. Xiong, Z. Wan, S. Qin, P. Shi, J. Wang, and Z. Wu, “A novel Class F fly ash-based geopolymer and its application in coal mine grouting," Advances in Civil Engineering, vol. 2020, pp. 1-12, 2020.

[29] S. L. Yang, M. Li, G. F. Song, Y. Yang, and F. Xie, "Optimization of face flexible bolting and grouting technology for longwall face support under difficult geological conditions," Energy Sci Eng, vol. 8, no. 4, pp. 1260-1270, 2019.

[30] M. Ahmaruzzaman, "A review on the utilization of fly ash," Progress in Energy and Combustion Science, vol. 36, no. 3, pp. 327-363, 2010.

[31] Z. Tauanov, S. Azat, and A. Baibatyrova, "A mini-review on coal fly ash properties, utilization and synthesis of zeolites," International Journal of Coal Preparation and Utilization, vol. 123 pages, 2020.

[32] T. Hemalatha and A. Ramaswamy, "A review on fly ash characteristics - towards promoting high volume utilization in developing sustainable concrete," Journal of Cleaner Production, vol. 147, pp. 546-559, 2017.

[33] A. R. Moran and H. Hettiarachchi, "Geotechnical characterization of mined clay from appalachian Ohio: challenges and implications for the clay mining industry," International Journal of Environmental Research and Public Health, vol. 8, no. 7, pp. 2640-2655, 2011.

[34] G. Wu, H. Bai, B. Du, L. Wu, S. He, and H. Li, "Study on the failure mechanism of clay layer overlying thin bedrock in coal seam mining," Environmental Earth Sciences, vol. 78, no. 10, 2019. 
[35] K. T. Crane and T. R. West, "Prioritizing grouting operations for abandoned underground coal mines, southwestern Indiana," Environmental and Engineering Geoscience, vol. 20, no. 4, pp. 325-334, 2014.

[36] P. G. A. Njock, J. Chen, G. Modoni, A. Arulrajah, and Y.-H. Kim, "A review of jet grouting practice and development," Arabian Journal of Geosciences, vol. 11, no. 16, 2018.

[37] S. F. Wang, Y. Tang, X. B. Li, and K. Du, "Analyses and predictions of rock cuttabilities under different confining stresses and rock properties based on rock indentation tests by conical pick," Transactions of Nonferrous Metals Society of China, vol. 31, no. 6, pp. 1766-1783, 2021.

[38] S.-f. Wang, Y. Tang, and S.-y. Wang, "Influence of brittleness and confining stress on rock cuttability based on rock indentation tests," Journal of Central South University, vol. 28, no. 9, pp. 2786-2800, 2021. 